\title{
Representing the Australian Heat Low in a GCM Using Different Surface and Cloud Schemes
}

\author{
Matthew M. Allcock and Duncan Ackerley \\ ARC Centre of Excellence for Climate System Science, School of Earth, Atmosphere and Environment, Monash University, \\ Clayton, VIC 3800, Australia \\ Correspondence should be addressed to Duncan Ackerley; duncan.ackerley@monash.edu
}

Received 9 April 2015; Accepted 16 September 2015

Academic Editor: Hiroyuki Hashiguchi

Copyright (C) 2016 M. M. Allcock and D. Ackerley. This is an open access article distributed under the Creative Commons Attribution License, which permits unrestricted use, distribution, and reproduction in any medium, provided the original work is properly cited.

\begin{abstract}
The high insolation during the Southern Hemisphere summer leads to the development of a heat low over north-west Australia, which is a significant feature of the monsoon circulation. It is therefore important that General Circulation Models (GCMs) are able to represent this feature well in order to adequately represent the Australian Monsoon. Given that there are many different configurations of GCMs used globally (such as those used as part of the Coupled Model Intercomparison Project), it is difficult to assess the underlying causes of the differences in circulation between such GCMs. In order to address this problem, the work presented here makes use of three different configurations of the Australian Community Climate and Earth System Simulator (ACCESS). The configurations incorporate changes to the surface parameterization, cloud parameterization, and both together (surface and cloud) while keeping all other parameterized processes unchanged. The work finds that the surface scheme has a larger impact on the heat low than the cloud scheme, which is caused by differences in the soil thermal inertia. This study also finds that the differences in the circulation caused by changing the cloud and surface schemes together are the linear sum of the individual perturbations (i.e., no nonlinear interaction).
\end{abstract}

\section{Introduction}

The high insolation and surface heating of the Australian land surface in summer (December, January, and February (DJF)) create a strong diurnal cycle in temperature and circulation [1-4]. During the daytime, solar heating of the land surface acts to warm the air in the low-level atmosphere, which then rises, lowering the surface pressure. This area of low pressure is known as a heat low. Conversely, as the surface cools at night, a stable nocturnal boundary layer forms, allowing the development of a low-level jet and convergence over the heat low [5]. The boundary layer becomes unstable in the morning (following surface heating), which initiates convection and a reduction in surface pressure as described above. Heat lows also occur in other semiarid areas of the world, for example, the Iberian Peninsula [6-9] and West Africa [10-13].

The heat low circulation is an important feature of the Australian monsoon [14], which resides in the north-west of the continent (see Figure 1(a), the circulation is centred at approximately $120^{\circ} \mathrm{E}$ and $22^{\circ} \mathrm{S}$ ). It is therefore important to represent the heat low accurately in general circulation models (GCMs) in order to correctly simulate the Australian monsoon system. Previous work by Ackerley et al. [15] shows that the diurnal change in the low-level circulation across the north-west Australian heat low is represented well in the Australian Community Climate and Earth System Simulator version 1.3 (ACCESS1.3). Moreover, Ackerley et al. [16] also show that other GCMs (available as part of the Coupled Model Intercomparison Project phase 5 (CMIP5) including ACCESS1.3 and ACCESS1.0) are also capable of simulating the correct diurnal variation in the low-level circulation. Nevertheless, the magnitudes of the simulated mean wind velocities around the heat low are different for each model by approximately 2-4 $\mathrm{m} \mathrm{s}^{-1}$ (approximately 50\%; see Figure 6 in [16]). Given the different configurations of the CMIP5 models, Ackerley et al. [16] do not attribute the differences in the heat low circulation to any specific parameterization scheme. Experiments in which changes are applied individually and 


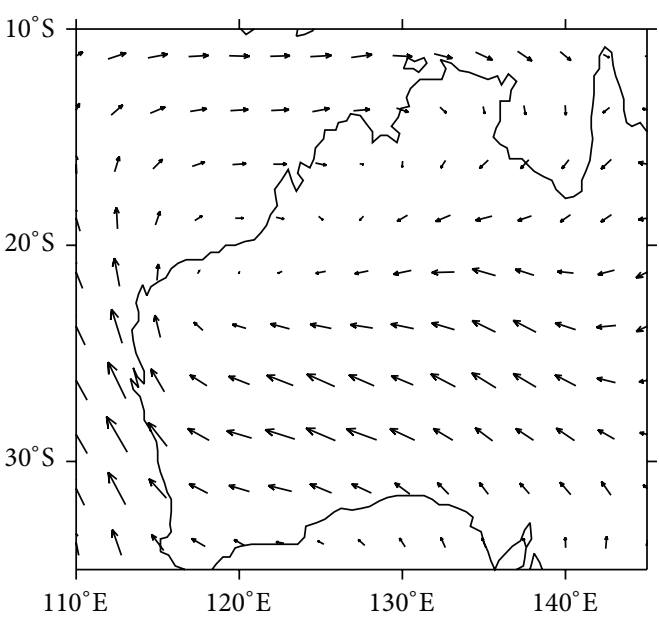

$\longrightarrow 4$

(a)

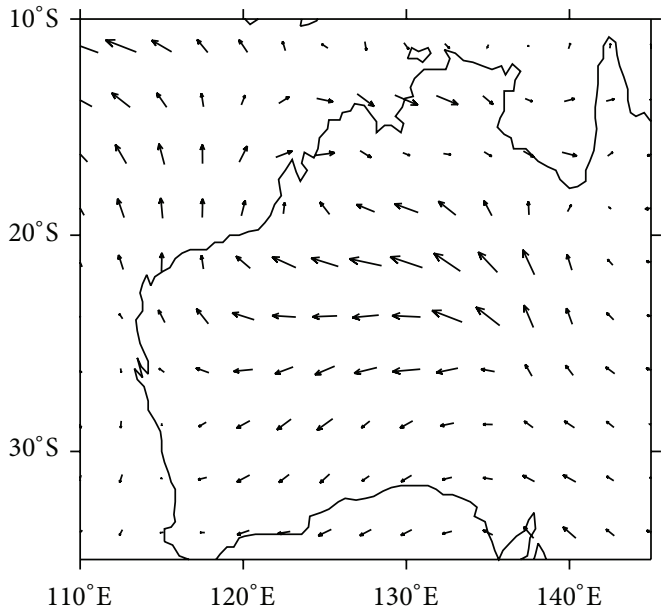

$\longrightarrow 2$

(c)

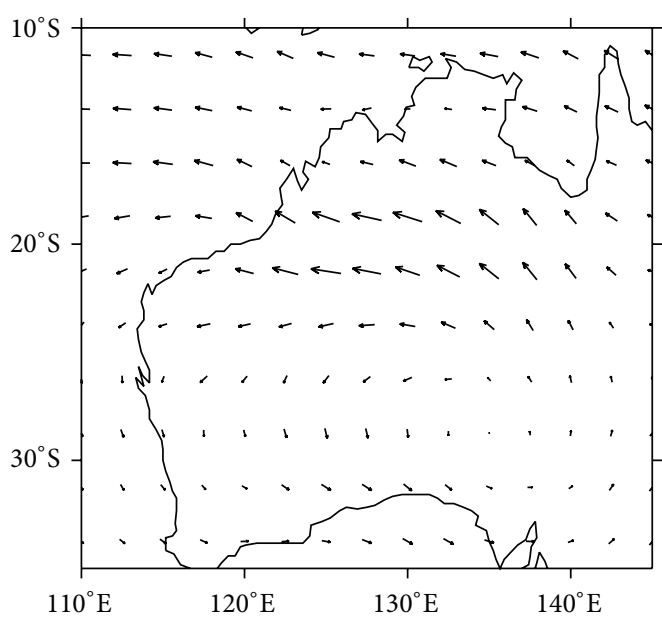

$\longrightarrow 2$

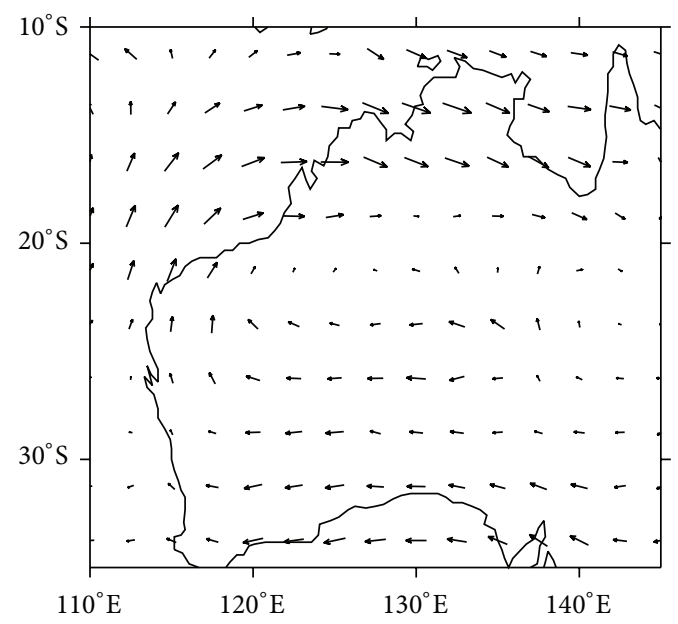

(b)

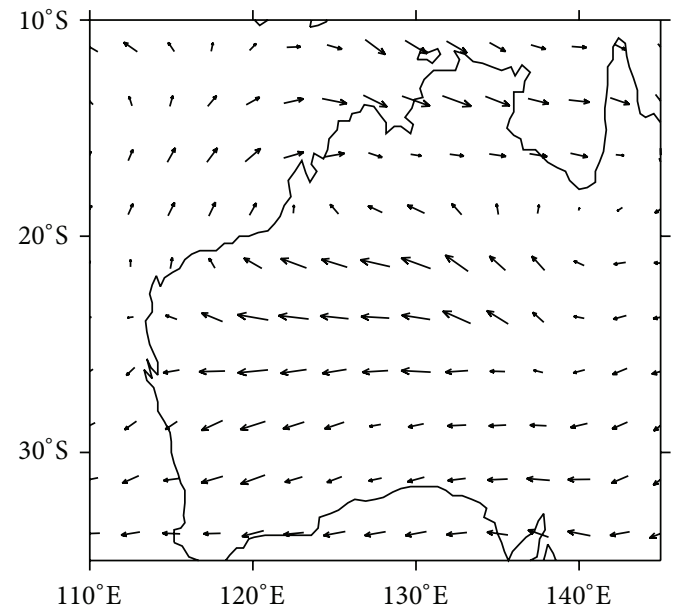

$\longrightarrow 2$

(d)

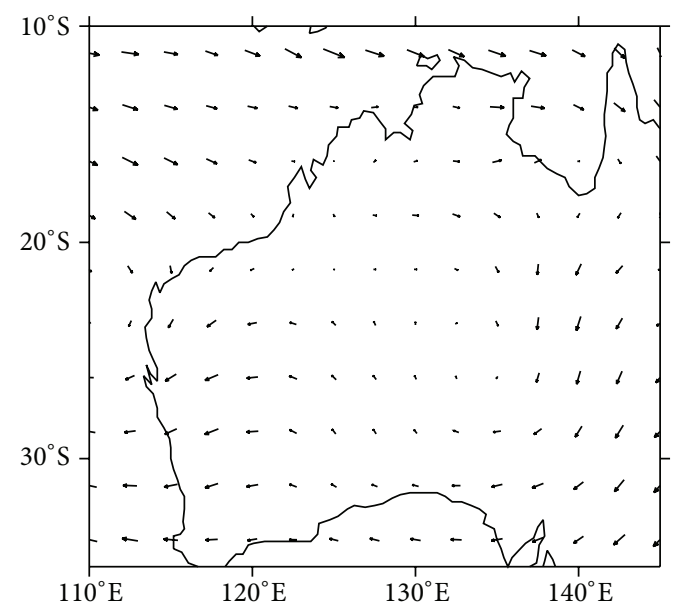

(f)

Figure 1: Climatological mean DJF circulation at $925 \mathrm{hPa}\left(\mathrm{m} \mathrm{s}^{-1}\right)$ for (a) ERA-Interim, (b) A1.0 minus ERA-Interim, (c) A1.1 minus ERAInterim, (d) A1.3 minus ERA-Interim, (e) A1.1 minus A1.0, and (f) A1.3 minus A1.1. 
in combination with the model physics would therefore be useful in order to help identify the important processes that cause the GCMs assessed by Ackerley et al. [16] to differ.

This study builds on the work by Ackerley et al. $[15,16]$ by evaluating the simulated north-west Australian heat low in three versions of ACCESS with different parameterizations (see Section 2). Therefore, by comparing each of the simulations against each other, this paper shows which of the physics changes has the largest impact on the north-west Australian heat low.

The aims of this paper are twofold:

(1) To identify and discuss the differences in the simulated summertime circulation over north-west Australia between three different configurations of ACCESS.

(2) To identify the physical processes within each of the model configurations that causes the differences in the circulation.

A description of the model configurations used in this study is given in Section 2 along with the experimental design and boundary conditions. The main results for the differences in the flow and temperature fields are given in Section 3 and a discussion of why those differences occur is given in Section 4 . The main conclusions and suggested further work are given in Section 5.

\section{Methods}

The Australian Community Climate and Earth System Simulator (ACCESS) is a series of coupled climate models developed in a partnership between the Commonwealth Scientific and Industrial Research Organisation (CSIRO) and the Bureau of Meteorology $[17,18]$. This model (ACCESS) is used extensively in climate research and is Australia's most comprehensive climate model.

The three configurations of ACCESS used in this study are ACCESS1.0 (from now A1.0), ACCESS1.1 (A1.1), and ACCESS1.3 (A1.3). A1.0 is considered as the base version of the model in this study. It utilises the Met Office Surface Exchange Scheme version 2 (MOSES2) land surface model [19] and atmospheric physics from the Hadley Centre Global Environment Model 2 (HadGEM2(r1.1), [20, 21]). A1.1 has the same atmospheric module as A1.0 but uses the Community Atmosphere Biosphere Land Exchange model version 1.8 (CABLE1.8, [19, 22, 23]) instead of MOSES. The main differences between MOSES and CABLE1.8 (which are described in more detail in [23]) applicable to this study are as follows:

(i) MOSES has four vertical levels (at $0.1 \mathrm{~m}, 0.25 \mathrm{~m}$, $0.65 \mathrm{~m}$, and $2.0 \mathrm{~m}$ depth) whereas CABLE1.8 has six vertical levels (at $0.022 \mathrm{~m}, 0.058 \mathrm{~m}, 0.154 \mathrm{~m}, 0.409 \mathrm{~m}$, $1.085 \mathrm{~m}$, and $2.872 \mathrm{~m}$ depth).

(ii) MOSES represents nine surface types (five vegetated and four nonvegetated) with each grid box split into nine tiles that can be set to any combination of the nine surface types.

(iii) CABLE1.8 represents thirteen surface types (of which 10 are vegetated) with each grid box split into five tiles that can be set to any combination of the thirteen surface types.

A1.3 also uses the CABLE1.8 surface scheme but differs from ACCESS1.1 in the representation of clouds. The main differences between the A1.1 (and A1.0) and the A1.3 cloud schemes are as follows:

(i) Cloud inhomogeneities are represented in A1.3 using the "Tripleclouds" scheme [24, 25] but are not represented in A1.0 or A1.1.

(ii) A1.0 and A1.1 use a diagnostic cloud scheme for both liquid and ice cloud fractions $[26,27]$.

(iii) A1.3 uses the Prognostic Cloud Prognostic Condensate scheme (PC2, [28-30]), which treats cloud liquid water and ice content, liquid and ice cloud fraction, and total cloud fraction as prognostic variables.

The different configurations of ACCESS will allow us to identify the impact of

(1) changing the land surface scheme (A1.1 relative to A1.0),

(2) changing the cloud scheme (A1.3 relative to A1.1),

(3) changing both the land surface and cloud schemes (A1.3 relative to $\mathrm{A1} .0$ ),

on the summertime circulation over north-west Australia. Given that the CMIP5 models assessed in Ackerley et al. [16] use many different combinations of parameterizations, this study presents an opportunity to identify whether the surface scheme, cloud scheme, or both together play the dominant role in governing the Australian heat low structure.

Each configuration of ACCESS (A1.0, A1.1, and A1.3) has been run using Atmospheric Model Intercomparison Project (AMIP, [31, 32]) prescribed monthly sea-surface temperatures and sea ice conditions from January 1978 to February 2001. The model was initiated with conditions on January 1, 1978, but the months from January 1978 to November 1979 were not used in this study to allow the models sufficient time to spin up. Model data are then used from December 1979 to February 2001 in the analysis below. Temperature and wind speed are taken from all DJFs and used to produce a climatological mean diurnal cycle for 0200, 0800, 1400, and 2000 Australian Western Standard Time (AWST, UTC+8 hr).

The DJF climatological mean $925 \mathrm{hPa}$ wind field from ERA-Interim reanalyses (1979-2008, [33]) is plotted in Figure 1(a). The centre of the heat low circulation can be seen at approximately $120^{\circ} \mathrm{E}$ and $22^{\circ} \mathrm{S}$ with easterly flow over most of the Australian continent. The differences between the wind field in A1.0, A1.1, and A1.3 and ERA-Interim are $1-2 \mathrm{~m} \mathrm{~s}^{-1}$ over most of the Australian continent (Figures 1(b)-1(d), resp.), which are comparable with the differences (i.e., $1-2 \mathrm{~m} \mathrm{~s}^{-1}$ ) already presented for the CMIP5 models (including A1.0 and A1.3) by Ackerley et al. [16]. Despite the differences in the simulated circulations relative to the reanalyses, the differences in the wind fields between each 


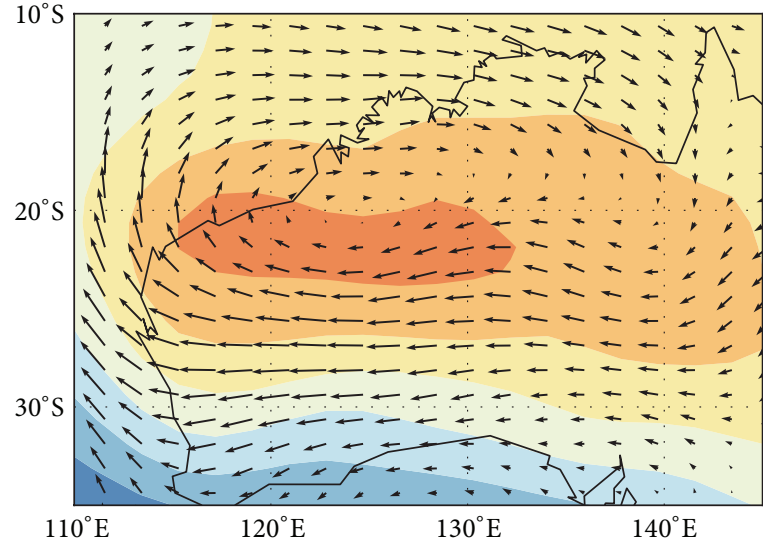

$\longrightarrow 10 \mathrm{~m} / \mathrm{s}$

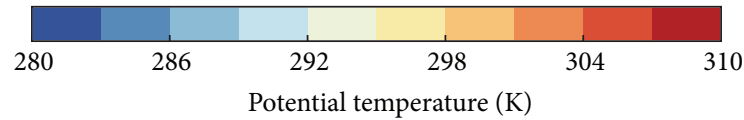

(a)

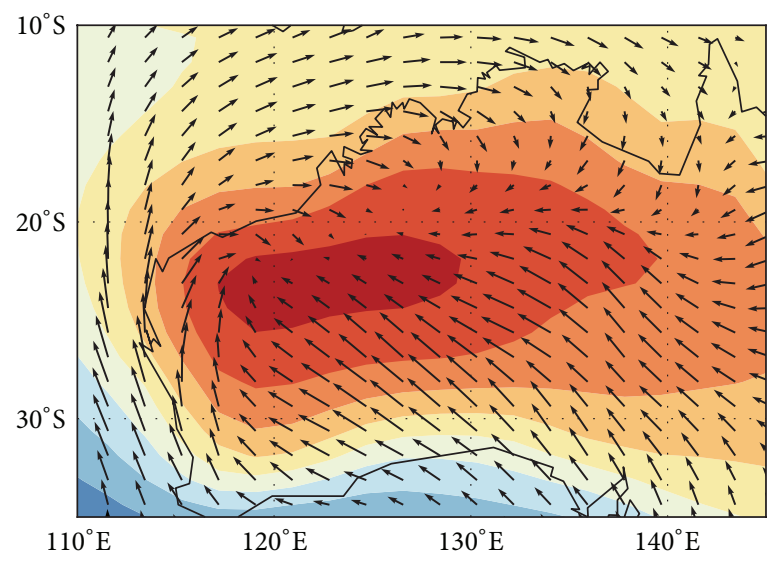

$\longrightarrow 10 \mathrm{~m} / \mathrm{s}$

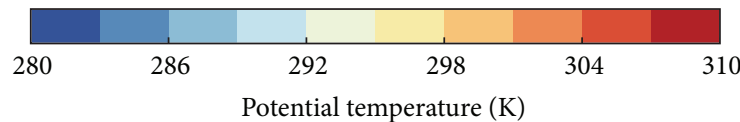

(c)

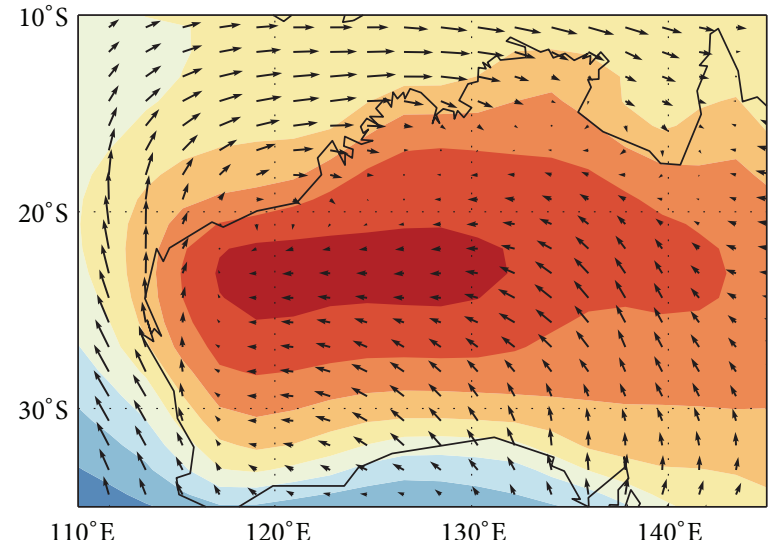

$\longrightarrow 10 \mathrm{~m} / \mathrm{s}$

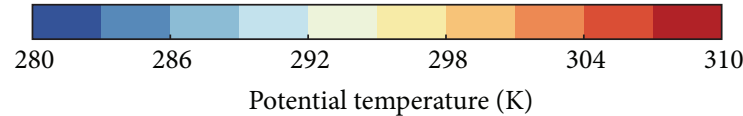

(b)

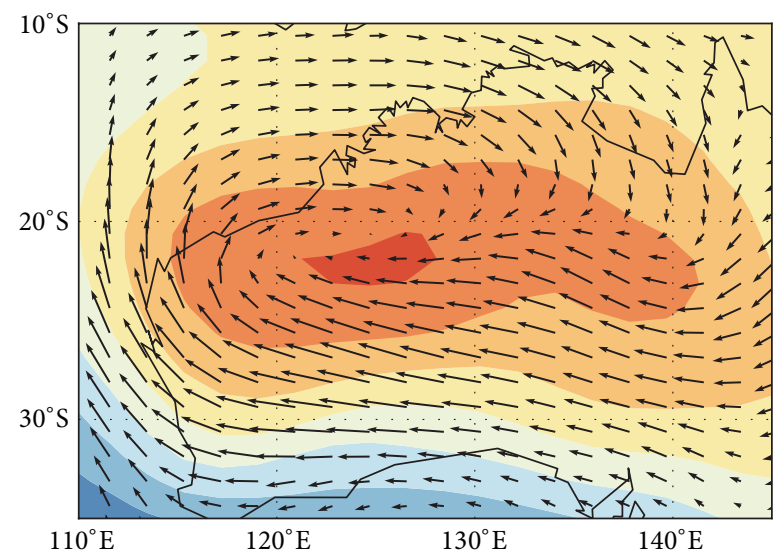

$\longrightarrow 10 \mathrm{~m} / \mathrm{s}$

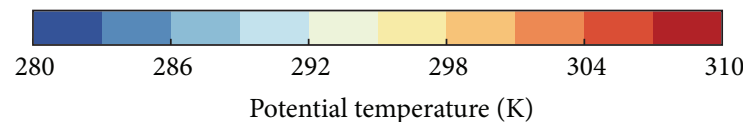

(d)

Figure 2: Climatological mean (1979-2001) potential temperature (K) at $925 \mathrm{hPa}$ in A1.0 at (a) 0800 AWST, (b) 1400 AWST, (c) 2000 AWST, and (d) 0200 AWST.

model configuration are also comparable with the differences relative to the observations (Figures $1(\mathrm{e})$ and $1(\mathrm{f})$ ). Therefore, this study will focus only on the differences between the model configurations and not the models and observations, which have already been shown in more detail by Ackerley et al. [15, 16], Bi et al. [19], and Kowalczyk et al. [22, 23].

\section{Results}

3.1. Diurnal Cycle in A1.0. The main climatological features of the A1.0 simulation are described in this section in order to provide a benchmark from which to look at the changes in circulation that are caused by the different model physics. The mean diurnal cycle of the temperature and horizontal wind at $925 \mathrm{hPa}$ is illustrated in Figure 2 for A1.0. The largest temperature change at $925 \mathrm{hPa}$ (approximately $6 \mathrm{~K}$ ) occurs between $120-130^{\circ} \mathrm{E}$ and $20-25^{\circ} \mathrm{S}$ between 0800 and 1400 AWST (Figures 2(a) and 2(b)). There is also a cyclonic circulation centred on $125^{\circ} \mathrm{E}$ and $20^{\circ} \mathrm{S}$ at 0800 AWST (Figure 2(a)), which weakens and turns towards the centre of the heat low as the low-level air heats up (Figure 2(b)). The change in circulation between 0800 and 1400 AWST is caused by increased low level drag from the presence of dry convection (as discussed in $[15,16]$ ).

The low-level temperature decreases (again, by approximately $6 \mathrm{~K}$ ) in the evening between 2000 and 0200 AWST 


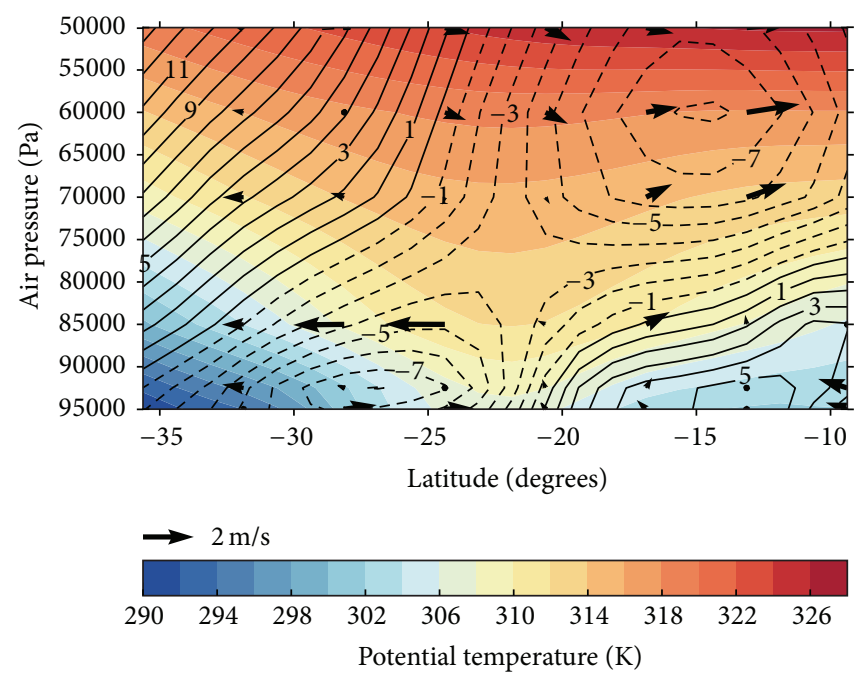

(a)

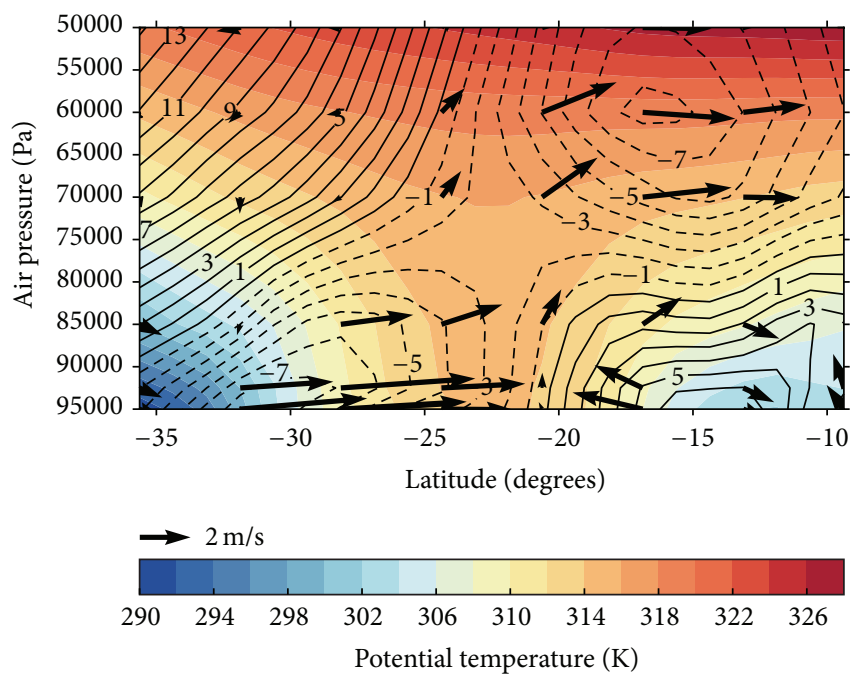

(c)

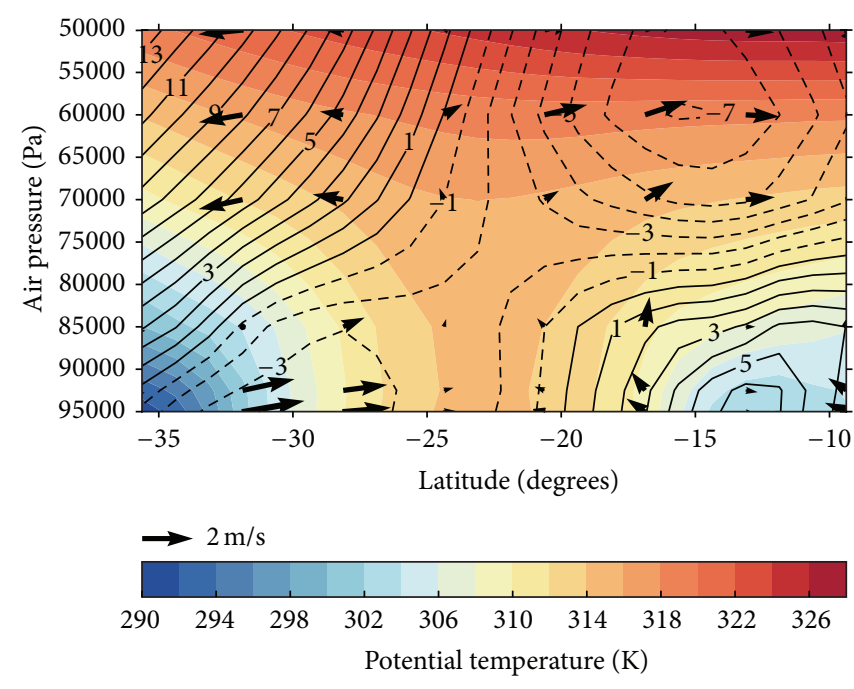

(b)

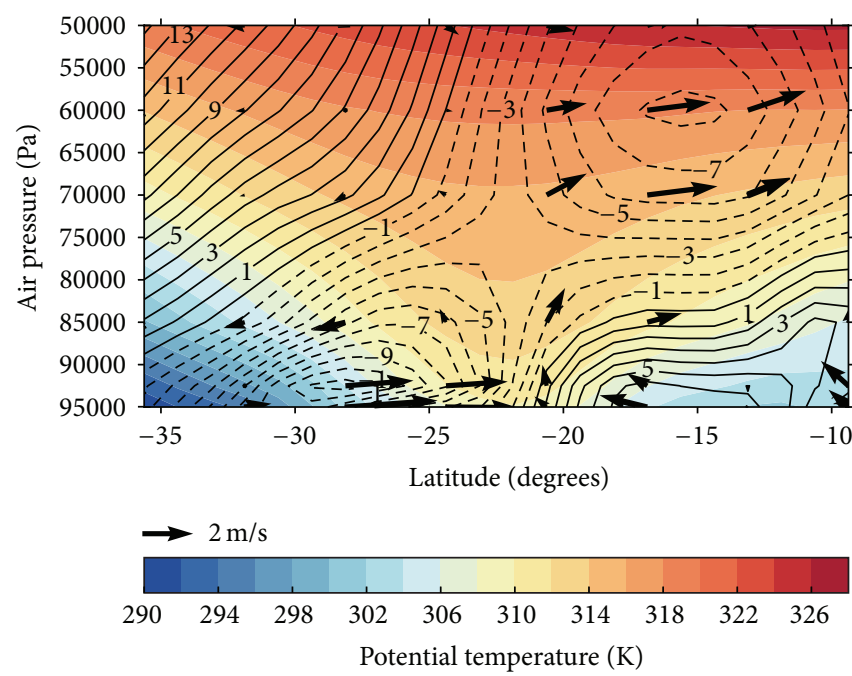

(d)

Figure 3: Climatological mean (1979-2001) potential temperature (K), horizontal and vertical wind ( $\mathrm{m} \mathrm{s}^{-1}$ ) along $125^{\circ} \mathrm{E}$ in $\mathrm{Al.0}$ at $(\mathrm{a})$ 0800 AWST, (b) 1400 AWST, (c) 2000 AWST, and (d) 0200 AWST. The colors indicate potential temperature and the black contours indicate the zonal winds, respectively. The dotted and solid black lines represent zonal flow into and out of the page, respectively. The vertical component is multiplied by a factor of 100 to make it visible.

(Figures 2(c) and 2(d)) as a result of radiative cooling after sunset. This cooling causes the nocturnal boundary layer to form, which reduces the low-level drag. The circulation responds by initially accelerating towards the centre of the heat low at 2000 AWST relative to 1400 AWST (cf. Figures 2(b) and 2(c)) before turning anticyclonically (i.e., away from the heat low centre) between 2000 AWST and 0200 AWST (cf. Figures 2(c) and 2(d)) as the flow tends towards geostrophic balance. The circulation is consistent with the results for A1.0 shown in Ackerley et al. [16].

In order to evaluate the vertical structure of the heat low, a vertical cross section of potential temperature and the wind field along $125^{\circ} \mathrm{E}$ is plotted in Figure 3. The surface heating and the subsequent convective mixing (just above the surface) disrupt the stable nocturnal boundary layer between 0800 and 1400 AWST and cause the isentropes to intersect with the surface (Figures 3(a) and 3(b)). This warm, lowlevel air rises parallel to the isentropes, causing cool inflow from the north and south (Figure 3(b)). The strongest radial flow into the heat low centre (approximately $4 \mathrm{~ms}^{-1}$ ) occurs around 2000 AWST (Figure 3(c)), which causes the strongest vertical velocities to occur. This low-level convergence at 2000 AWST is accompanied by increased cyclonic circulation between 950 and $900 \mathrm{hPa}$ and a strengthening of the southerly and easterly flow at approximately 700 to $600 \mathrm{hPa}$ (Figures $2(\mathrm{c})$ and $3(\mathrm{c}))$. The structure of the simulated temperature and circulation features in A1.0 are consistent with the features presented by Spengler and Smith [34] for heat low circulations over flat terrain.

3.2. A1.1 Relative to A1.0. The corresponding plots for A1.1 are not included because the main circulation and temperature 
features are very similar to those plotted for A1.0. Instead, the differences in the circulation between A1.1 and A1.0 are now considered to identify the impact of using the CABLE1.8 surface scheme instead of MOSES.

The differences in the mean diurnal cycle of the horizontal winds and air temperature at $925 \mathrm{hPa}$ are plotted in Figures 4(a)-4(d). At 0800 AWST (Figure 4(a)), A1.1 is warmer than A1.0 by approximately $0.1-1.0 \mathrm{~K}$ westward of $130^{\circ} \mathrm{E}$ with stronger easterly flow over much of the land surface. By 1400 AWST (Figure 4(b)), however, A1.1 is cooler than A1.0 by approximately $1.0 \mathrm{~K}$ over much of Australia. The easterly anomalies remain present but weaken (by approximately 3-4 $\mathrm{m} \mathrm{s}^{-1}$ ) between 0800 and 1400 AWST (cf. Figures 4(a) and 4(b)). At 2000 AWST (Figure 4(c)), the differences in $925 \mathrm{hPa}$ temperature are almost zero westward of $130^{\circ} \mathrm{E}$ and southward of $20^{\circ} \mathrm{S}$; however, northward of $20^{\circ} \mathrm{S}$, A1.1 is approximately $1 \mathrm{~K}$ warmer than A1.0. A1.1 then becomes warmer than $\mathrm{A} 1.0$ by 0.5 to $1.5 \mathrm{~K}$ westward of $130^{\circ} \mathrm{E}$ by 0200 AWST (Figure 4(d)). The easterly anomalies in A1.1 relative to A1.0 are at their strongest (approximately $5 \mathrm{~m} \mathrm{~s}^{-1}$ ) at 2000 and 0200 AWST northward of $20^{\circ} \mathrm{S}$ and appear to be more divergent over the heat low.

The vertical cross sections of potential temperature and the tangential, radial, and vertical winds in A1.1 relative to A1.0 are plotted in Figures 4(e)-4(h). The warmer temperatures northward of $20^{\circ} \mathrm{S}$ at $925 \mathrm{hPa}$ extend vertically to approximately $750 \mathrm{hPa}$ at all times (Figures $4(\mathrm{e})-$ $4(\mathrm{~h})$ ), although the anomalies are weakest at 1400 AWST (Figure 4(f)) and strongest at 0200 AWST (Figure 4(h)). The cold anomaly southward of $20^{\circ} \mathrm{S}$ at $925 \mathrm{hPa}$ extends from the surface to $650 \mathrm{hPa}$ at 1400 AWST where it connects with another cold anomaly above (Figure 4(f)). The radial wind anomalies are directed away from the centre of the heat low (at approximately $22.5^{\circ} \mathrm{S}$ ), which is indicative of reduced convergence during the day and night in A1.1 relative to A1.0 (see Figures 4(e)-4(h)).

3.3. A1.3 Relative to A1.1. The differences in circulation between A1.3 and A1.1 are considered in this section to identify the impact of changes to the cloud scheme on the heat low. The $925 \mathrm{hPa}$ temperatures are typically $0.5-1.5 \mathrm{~K}$ cooler in A1.3 relative to A1.1 with the largest negative anomalies at 1400 and 2000 AWST (Figures 5(b) and 5(c)) and the smallest negative anomalies at 0800 AWST (Figure 5(a)). The differences in the $925 \mathrm{hPa}$ flow are typically $1-2 \mathrm{~m} \mathrm{~s}^{-1}$ with weak easterly anomalies at the western coast of Australia and northerly (southerly) anomalies at 0800-1400 AWST (20000200 AWST) around $140^{\circ} \mathrm{E}$.

A vertical cross section of the temperature and circulation fields along $125^{\circ} \mathrm{E}$ is plotted in Figures 5(e)-5(h) for A1.3 relative to A1.0. The cold anomalies at $925 \mathrm{hPa}$ extend from the surface to approximately $800 \mathrm{hPa}$ and vary little throughout the day (except below $900 \mathrm{hPa}$ ). Moreover, the air temperatures are $1-2 \mathrm{~K}$ warmer in A1.3 relative to A1.1 above the cold anomaly. Again, there is little diurnal change to the temperatures above $750 \mathrm{hPa}$. Similarly, there is little change in the tangential wind field at $125^{\circ} \mathrm{E}$ (approximately within $\pm 1 \mathrm{~m} \mathrm{~s}^{-1}$ ); however, the radial wind strengthens towards the centre of the heat low at all levels between 0800 and 1400 AWST (Figures 5(e) and 5(f)) before weakening towards 0200 AWST (Figures 5(g) and 5(h)). The strengthening of the radial wind onshore suggests that there is stronger convergence over the land during the day in A1.3 relative to A1.1.

3.4. A1.3 Relative to A1.0. As with A1.1, A1.3 is cooler (by approximately $1.5 \mathrm{~K}$ ) at $925 \mathrm{hPa}$ over much of Australia at 1400 AWST (Figure 6(b)) before warming by approximately $0.1-0.5 \mathrm{~K}$ over the north-west of the continent overnight (Figure 6(d)). The A1.3 simulation is also more easterly at $925 \mathrm{hPa}$ over the majority of the Australian land mass throughout the day with the strongest flow anomalies located near $20^{\circ} \mathrm{S}$ (approximately $3 \mathrm{~m} \mathrm{~s}^{-1}$ ).

The negative temperature anomalies in $\mathrm{A} 1.3$ relative to A1.0 extend from the surface to $700 \mathrm{hPa}$ and are largest in magnitude at 1400 AWST (Figure 6(f)). The low-level (below $900 \mathrm{hPa}$ ) warm anomaly in A1.3 relative to A1.0 develops and strengthens to approximately $+0.6 \mathrm{~K}$ by 0200 AWST (cf. Figures 6(f) $-6(\mathrm{~h})$ ) and persists to 0800 AWST (Figure 6(a)). Above $700 \mathrm{hPa}$ the potential temperature is typically $1-2 \mathrm{~K}$ higher in A1.3 relative to A1.0. The stronger $925 \mathrm{hPa}$ easterly flow in A1.3 relative to A1.0 at 0200 AWST (Figure 6(d)) is restricted to below $750 \mathrm{hPa}$. Moreover, the differences in the radial flow in A1.3 relative to A1.0 indicate that there is weaker nocturnal convergence over the land at 2000 AWST (Figure 6(g)) in A1.3.

\section{Discussion}

4.1. A1.1 Relative to A1.0. The main difference in the diurnal cycle between A1.1 and A1.0 is that the low-level atmosphere (below approximately $800 \mathrm{hPa}$ ) over the heat low is cooler during the day and warmer overnight in A1.1 compared with A1.0 (see Figure 4). To illustrate this, the differences in $925 \mathrm{hPa}$ temperatures across consecutive 6-hour periods are plotted in Figure 7. From 0800 to 1400 AWST A1.1 warms by $4.0-7.0 \mathrm{~K}$ over most of Australia whereas the $925 \mathrm{hPa}$ temperatures increase by $5.0-8.0 \mathrm{~K}$ in $\mathrm{A} 1.0$ (and is consequently hotter) by 1400 AWST. Between 1400 to 2000 AWST, A1.1 and A1.0 both warm by similar amounts (approximately 1.0-2.0 K, Figures 7(b) and 7(f)); however, between 2000 and 0200 AWST A1.0 cools down faster than A1.1 and is consequently cooler overnight. The diurnal range in the $925 \mathrm{hPa}$ temperatures is therefore smaller in A1.1 than A1.0.

Dai et al. [35] have shown that the diurnal temperature range in summer (taken from station observations) is reduced when there is increased cloud cover, precipitation, and soil moisture. Therefore, the reduced diurnal temperature range may be caused by higher cloud cover fractions or precipitation in A1.1 relative to A1.0. The climatological mean precipitation and cloud cover for A1.0 and A1.1 are plotted in Figures 8(a) and 8(b) with the difference in precipitation and cloud cover in A1.1 relative to A1.0 in Figures 8(d) and $8(\mathrm{~g})$, respectively. A1.1 is drier and less cloudy than A1.0 over the whole of west Australia, which suggests there will be more solar radiation absorbed at the surface during the day, reduced latent heating, and more terrestrial radiation lost to space at night. A1.1 should therefore have a larger 


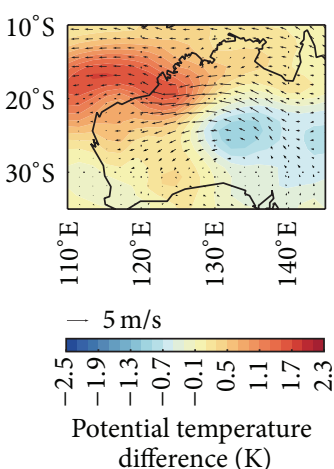

(a)

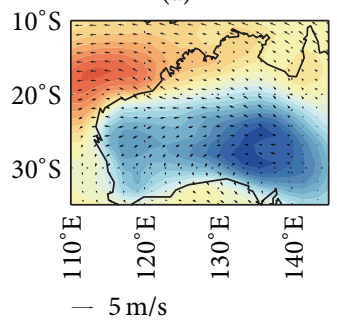

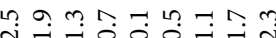

i $\rightarrow 00$ i

Potential temperature difference $(\mathrm{K})$

(b)

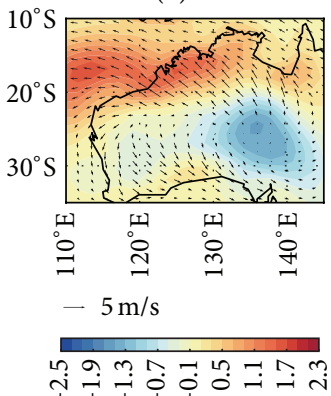

$17 \uparrow 0_{1}$

Potential temperature difference (K)

(c)

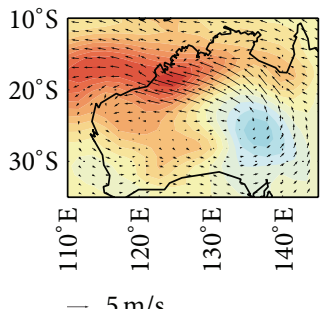

$\rightarrow 5 \mathrm{~m} / \mathrm{s}$

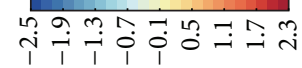

Potential temperature difference $(\mathrm{K})$

(d)

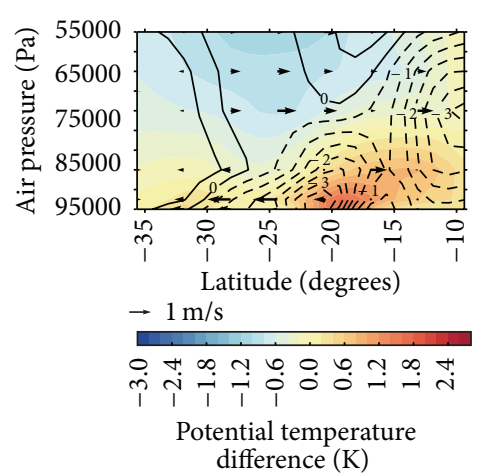

(e)

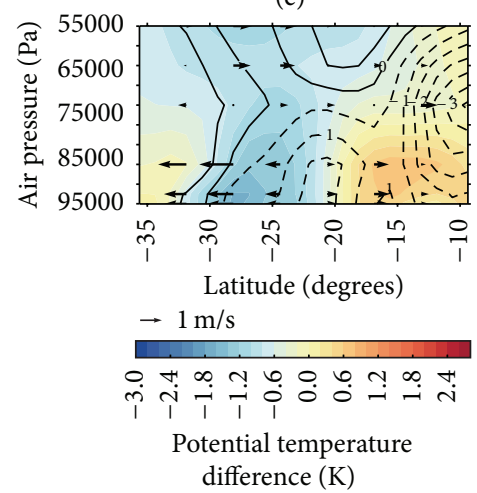

(f)

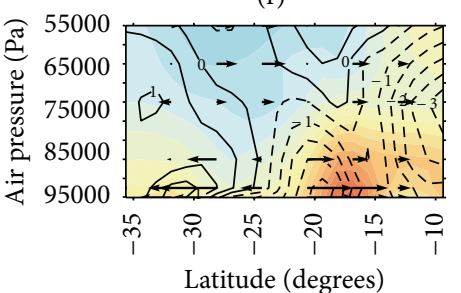

$\rightarrow 1 \mathrm{~m} / \mathrm{s}$

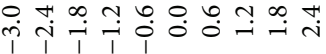

Potential temperature difference $(\mathrm{K})$

(g)

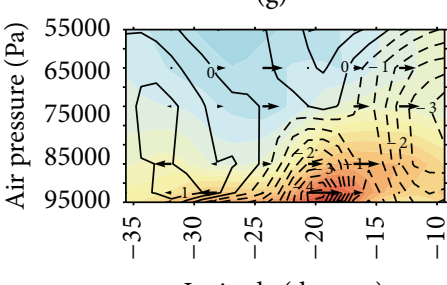

Latitude (degrees)

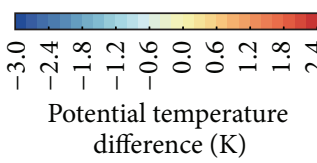

(h)

Figure 4: (a)-(d) show the difference in climatological mean (1979-2001) potential temperature (K) and horizontal wind speed (m $\mathrm{s}^{-1}$ ) at $925 \mathrm{hPa}$ between A1.1 and A1.0 at 0800, 1400, 2000, and 0200 AWST, respectively. (e)-(h) show the difference in potential temperature and horizontal wind speed at $125^{\circ} \mathrm{E}$ between A1.1 and A1.0 at 0800, 1400, 2000, and 0200 AWST, respectively. The colored contours show the difference in potential temperature. The meridional and vertical wind speeds are indicated by the arrows (scale under each figure) and the zonal wind speeds are shown as the black contours. The dotted and solid black lines represent the zonal flow into and out of the page, respectively. The vertical component is multiplied by a factor of 100 to make it visible. 


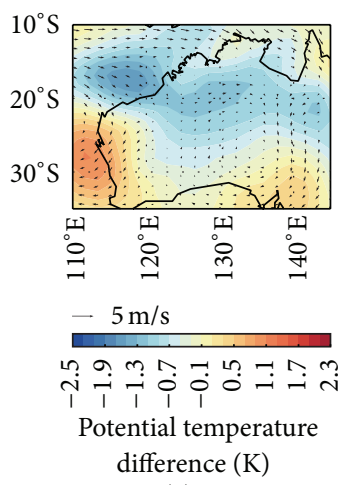

(a)

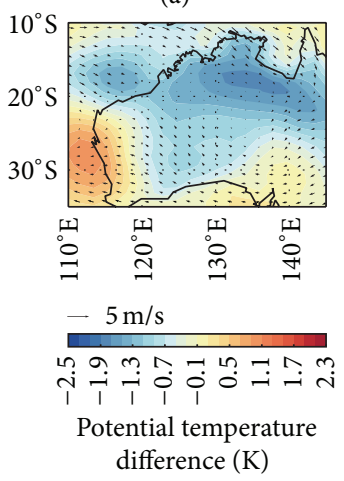

(b)

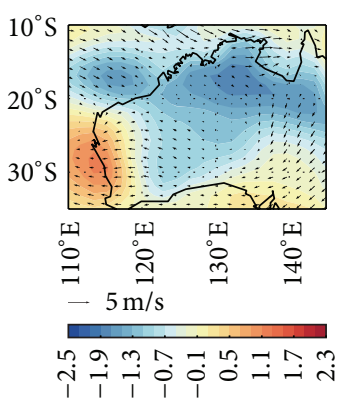

Potential temperature difference (K)

(c)

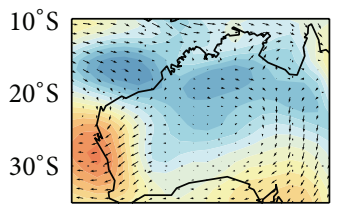

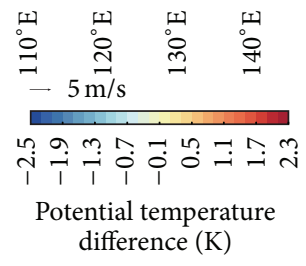

(d)

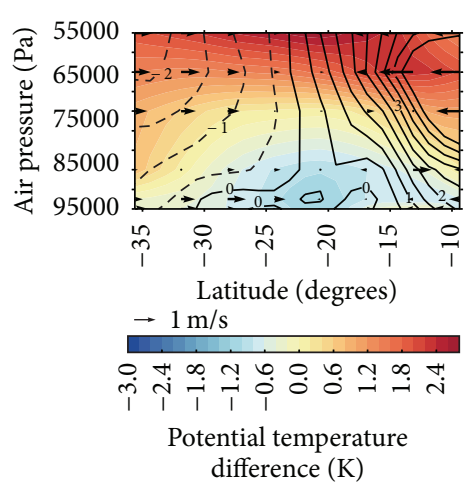

(e)

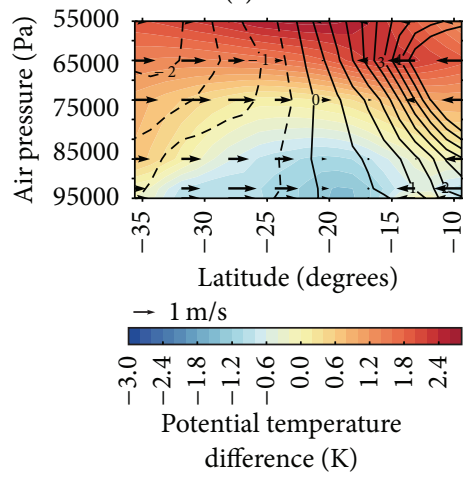

(f)

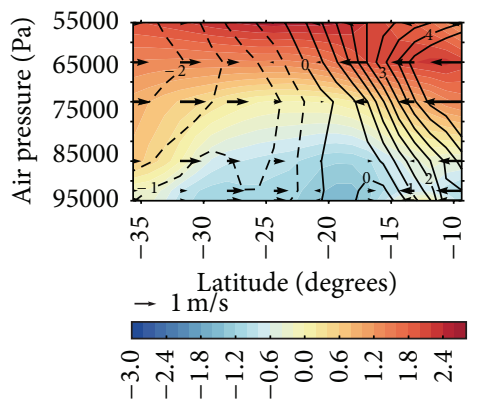

Potential temperature difference (K)

(g)

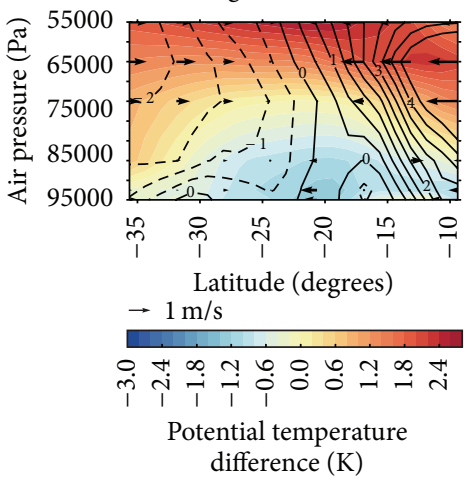

(h)

FIGURE 5: (a)-(d) show the difference in climatological mean (1979-2001) potential temperature (K) and horizontal wind speed ( $\mathrm{m} \mathrm{s}^{-1}$ ) at $925 \mathrm{hPa}$ between A1.3 and A1.1 at 0800, 1400, 2000, and 0200 AWST, respectively. (e)-(h) show the difference in potential temperature and horizontal wind speed at $125^{\circ}$ E between A1.3 and A1.1 at 0800, 1400, 2000, and 0200 AWST, respectively. The colored contours show the difference in potential temperature. The meridional and vertical wind speeds are indicated by the arrows (scale under each figure) and the zonal wind speeds are shown as the black contours. The dotted and solid black lines represent the zonal flow into and out of the page, respectively. The vertical component is multiplied by a factor of 100 to make it visible. 


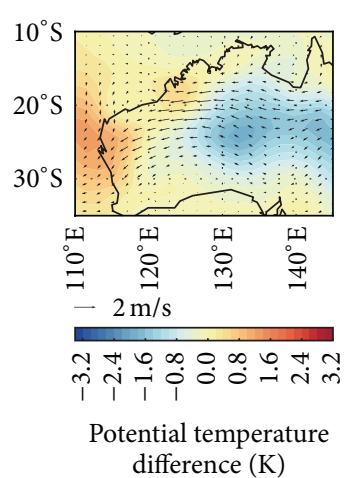

(a)

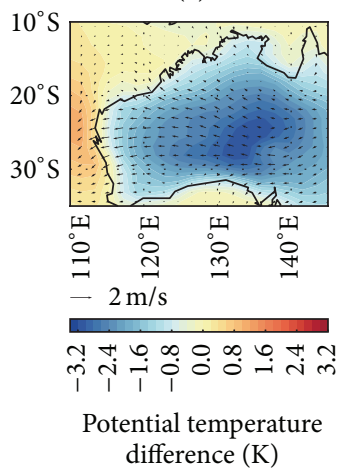

(b)

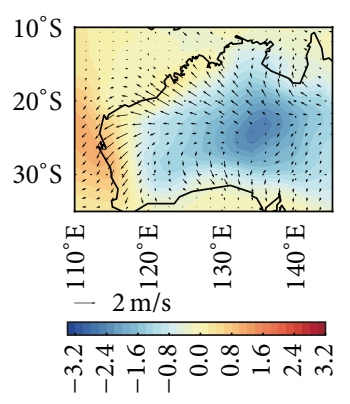

Potential temperature difference $(\mathrm{K})$

(c)

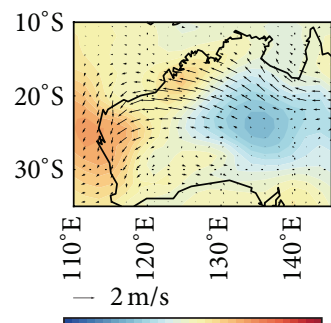

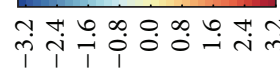

Potential temperature difference $(\mathrm{K})$

(d)

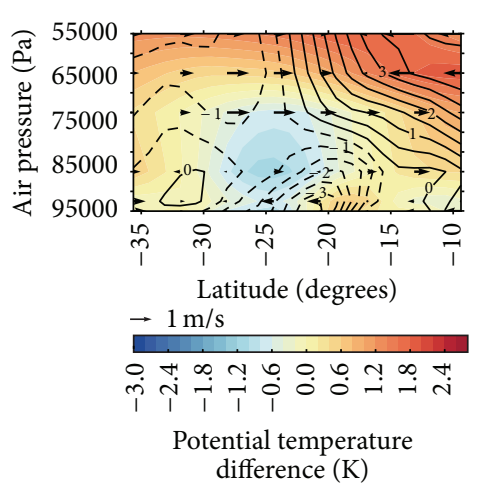

(e)

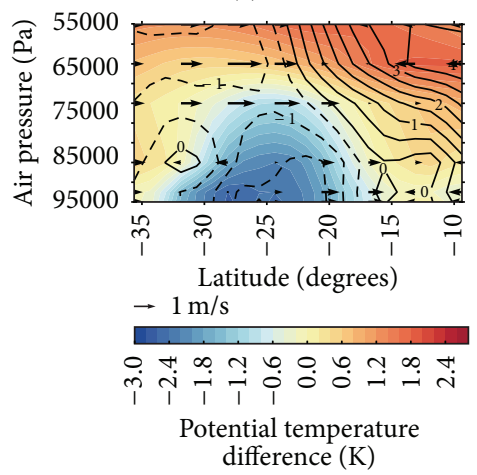

(f)

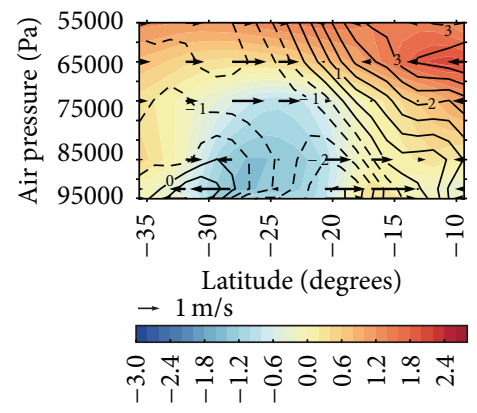

Potential temperature difference $(\mathrm{K})$

(g)

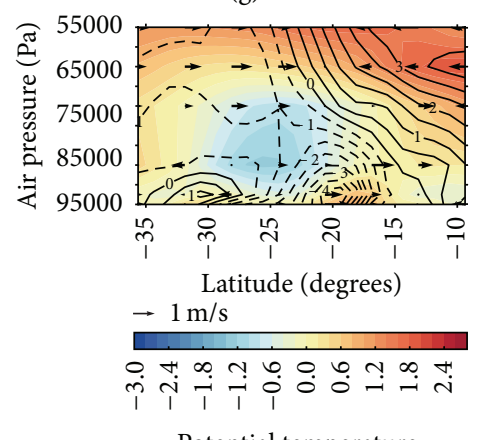

Potential temperature difference $(\mathrm{K})$

(h)

Figure 6: (a)-(d) show the difference in climatological mean (1979-2001) potential temperature (K) and horizontal wind speed (m $\mathrm{s}^{-1}$ ) at $925 \mathrm{hPa}$ between A1.3 and A1.0 at 0800, 1400, 2000, and 0200 AWST, respectively. (e)-(h) show the difference in potential temperature and horizontal wind speed at $125^{\circ} \mathrm{E}$ between A1.3 and A1.0 at 0800, 1400, 2000, and 0200 AWST, respectively. The colored contours show the difference in potential temperature. The meridional and vertical wind speeds are indicated by the arrows (scale under each figure) and the zonal wind speeds are shown as the black contours. The dotted and solid black lines represent the zonal flow into and out of the page, respectively. The vertical component is multiplied by a factor of 100 to make it visible. 


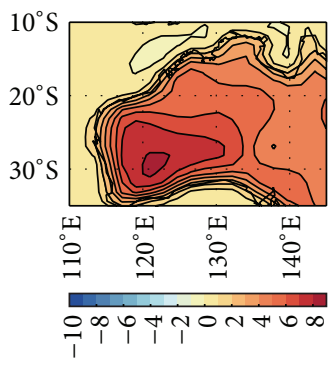

Temperature difference (K)

(a) 1400-0800 A1.0

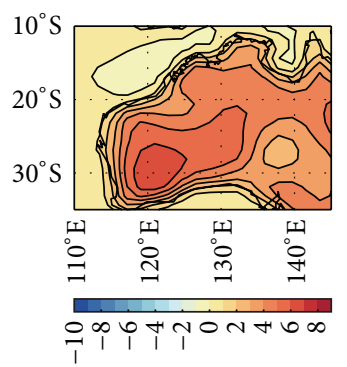

Temperature difference $(\mathrm{K})$

(e) 1400-0800 A1.1

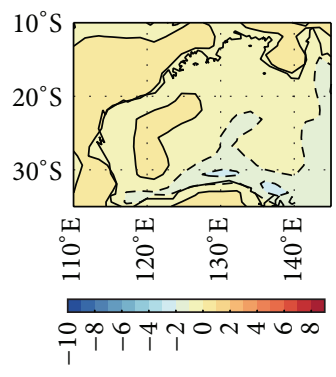

Temperature difference (K)

(b) 2000-1400 A1.0

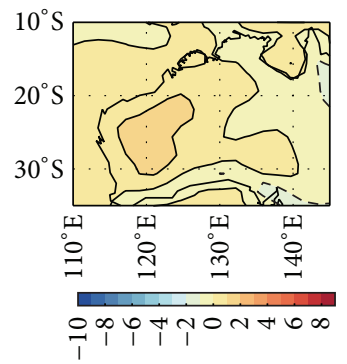

Temperature difference $(\mathrm{K})$

(f) 2000-1400 A1.1

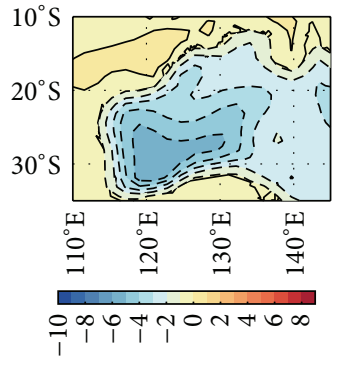

Temperature difference (K)

(c) 0200-2000 A1.0

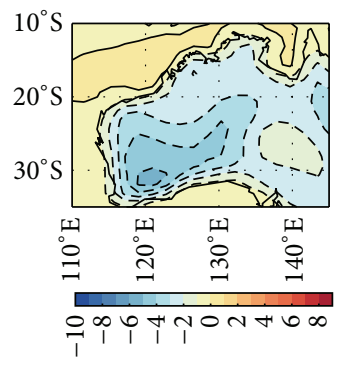

Temperature difference (K)

(g) 0200-2000 A1.1

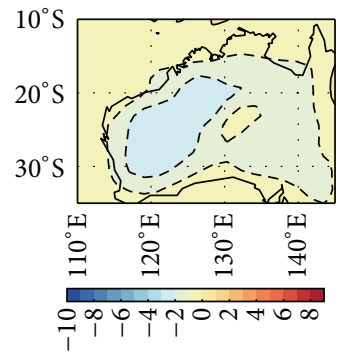

Temperature difference $(\mathrm{K})$

(d) 0800-0200 A1.0

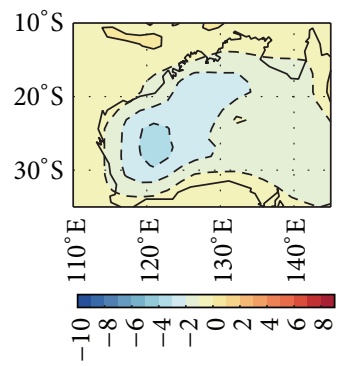

Temperature difference (K)

(h) 0800-0200 A1.1

Figure 7: The difference in air temperature (K) at $925 \mathrm{hPa}$ between (a and e) 1400 and 0800, (b and f) 2000 and 1400 , (c and g) 0200 and 2000, and (d and h) 0800 and 0200. (a)-(d) are from A1.0 and (e-h) are from A1.1.

diurnal temperature range than A1.0 (to first order) given the differences in cloud cover and precipitation between the two simulations. It is therefore unlikely that precipitation or cloud cover is playing the dominant role in causing the differences in the diurnal temperature range in A1.1 relative to A1.0.

The differences in air temperature below $850 \mathrm{hPa}$ may therefore be caused by the thermal properties of the land surface in each model. To illustrate this, the differences in the diurnal cycle of the downward surface net radiation $\left(D_{\text {NETdn }}\right)$ budget between A1.1 and A1.0 are plotted in Figure 9, first column (3-hour means centred on 0930, 1230, 1530, 1830, 2130, 0030, 0330, and 0630 AWST). Between 0500 and 1400 AWST (Figure 9: 0630, 0930, and 1230) there is a higher net radiative flux into the land surface in A1.1 relative to A1.0. Conversely, in the afternoon and overnight, the radiative flux from the surface to the atmosphere is higher in A1.1 than A1.0 (Figure 9, 1530 to 0330). The differences in the downward net short-wave radiative flux $\left(D_{\mathrm{Swdn}}\right.$, column 2$)$, net long-wave radiative flux ( $D_{\text {LWdn }}$, column 3$)$, sensible heat flux $\left(D_{\mathrm{Hdn}}\right.$, column 4$)$, and latent heat flux $\left(D_{\mathrm{LEdn}}\right.$, column 5) for A1.1 relative to A1.0 are also plotted in Figure 9 to investigate this further. The $D_{\text {SWdn }}$ is larger in A1.1 than A1.0 over Western Australia by $5-25 \mathrm{~W} \mathrm{~m}^{-2}$ around 0930, 1230, and 1530 (Figure 9, column 2), which is consistent with the lower cloud cover fraction in A1.1 (Figure 8(g)). The negative anomaly centred on $140^{\circ} \mathrm{E}$ is consistent with a small area of higher surface albedo in A1.1 relative to A1.0; however, over most of the continent there is more absorbed solar radiation in A1.1 relative to A1.0, which should act to warm the low-level atmosphere in A1.1.
The values of $D_{\text {LWdn }}$ are consistently lower in A1.1 relative to A1.0, which suggests that the upwards long-wave radiation is higher in A1.1 (Figure 9, column 3). Increased longwave emission from the surface should warm the low-level atmosphere more in A1.1 compared to A1.0. Despite the larger upward long-wave radiative flux in A1.1 relative to A1.0, the upward surface sensible and latent heat fluxes are weaker in A1.1 relative to A1.0 at 0930, 1230, and 1530 (Figure 9, columns 4 and 5: positive downward anomalies are indicative of weaker upward values during the day). The large positive $D_{\text {Hdn }}$ and $D_{\text {LEdn }}$ cause the positive $D_{\text {NETdn }}$ around 0930 and 1230 and are indicative of the soil in A1.1 retaining more of this energy than A1.0. Therefore there is less energy available to heat the lower atmosphere, which causes A1.1 to be cooler at low levels during the day (Figure 4(b)).

At night both the contributions from $D_{\text {Swdn }}$ and $D_{\text {LEdn }}$ diminish to almost zero whereas $D_{\mathrm{Hdn}}$ reverses from positive to negative by 1830 (Figure 9). The negative $D_{\mathrm{Hdn}}$ and $D_{\mathrm{LWdn}}$ values in A1.1 relative to A1.0 overnight are indicative of the surface acting to warm the lower atmosphere and are consistent with the higher nocturnal temperatures in A1.1 (Figure 4(d)).

The differences in the radiative fluxes throughout the diurnal cycle suggest that the land surface in A1.1 has a higher thermal inertia than A1.0, which results in lower surface temperatures during the day (despite more radiation being absorbed by the surface) and higher temperatures overnight (the land surface takes longer to cool). A study by AïMesbah et al. [36] showed that soil thermal inertia is likely to be the dominant factor that drives the differences in 


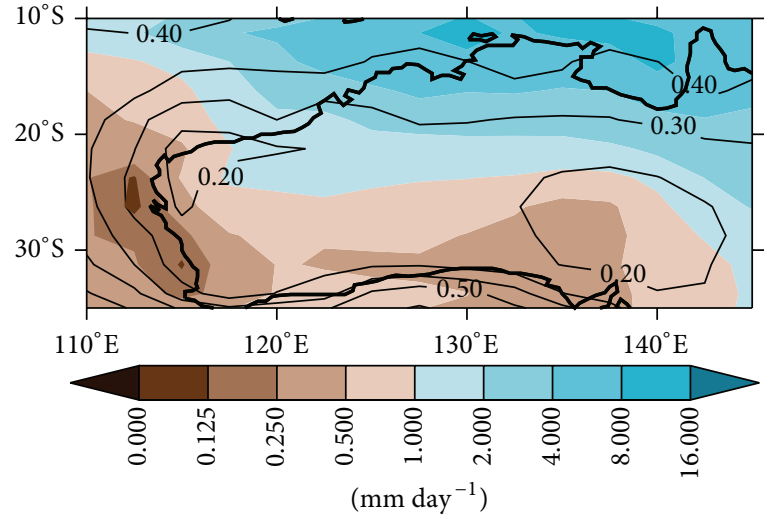

(a) pr and clt A1.0
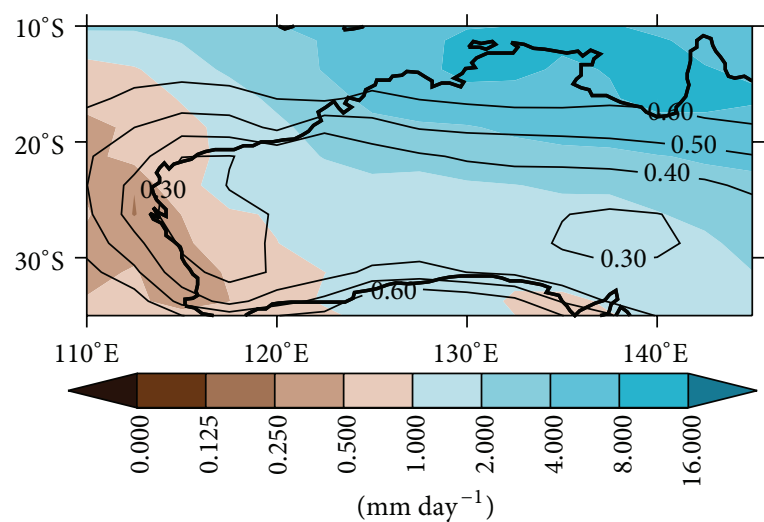

(c) pr and clt Al.3

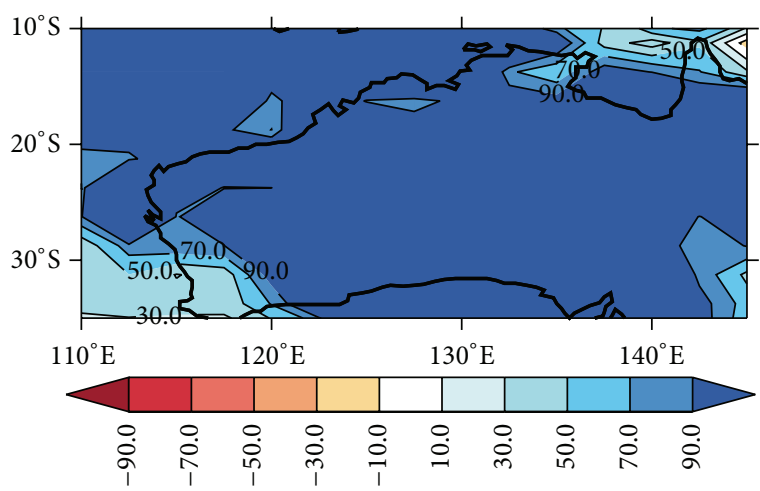

(\%)

(e) $D_{\text {pr }}$ A1.3-A1.1
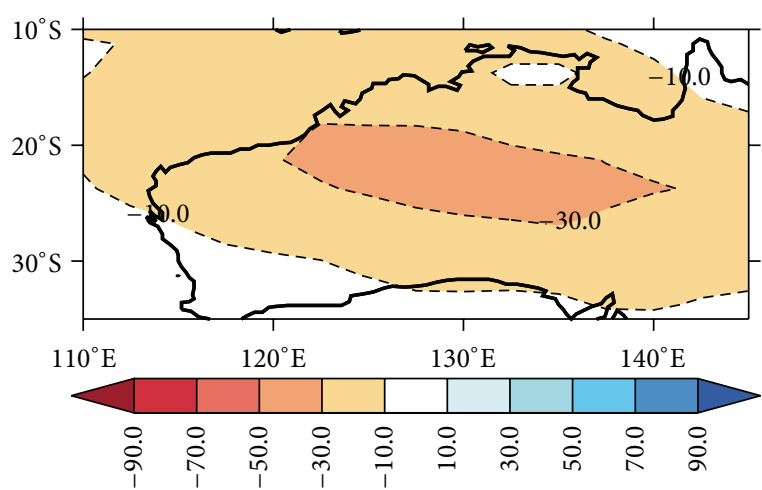

(\%)

(g) $\mathrm{DA}_{\mathrm{c}}$ A1.1-A1.0

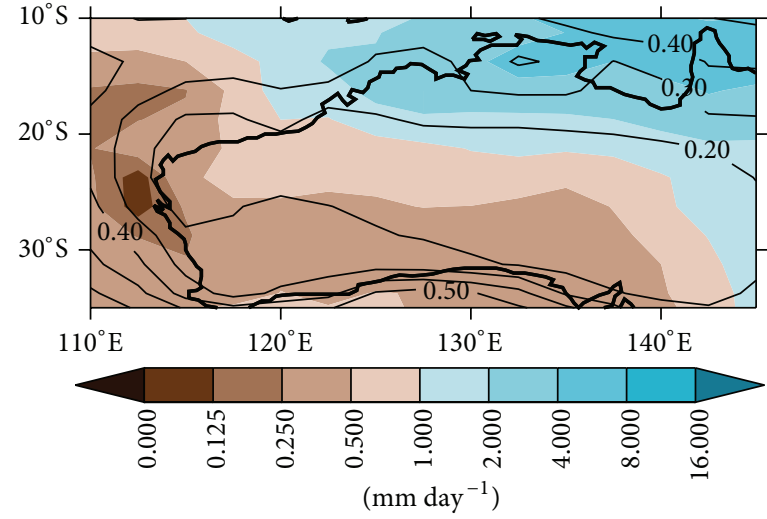

(b) pr and clt Al.1

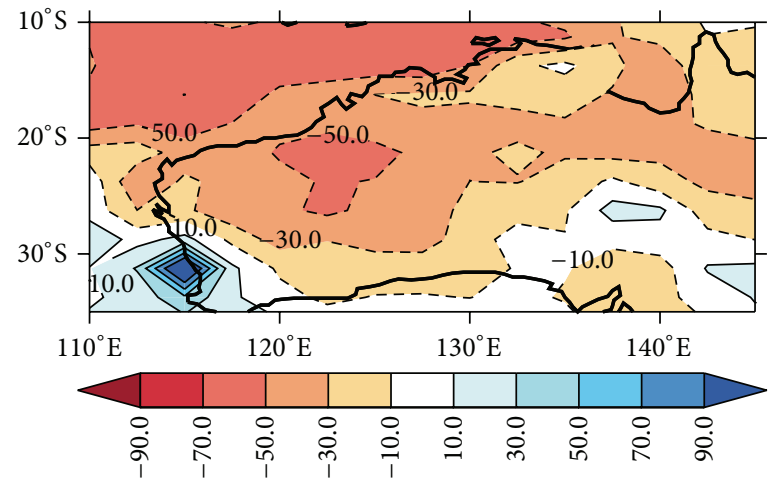

(\%)

(d) $D_{\text {pr }}$ Al.1-A1.0

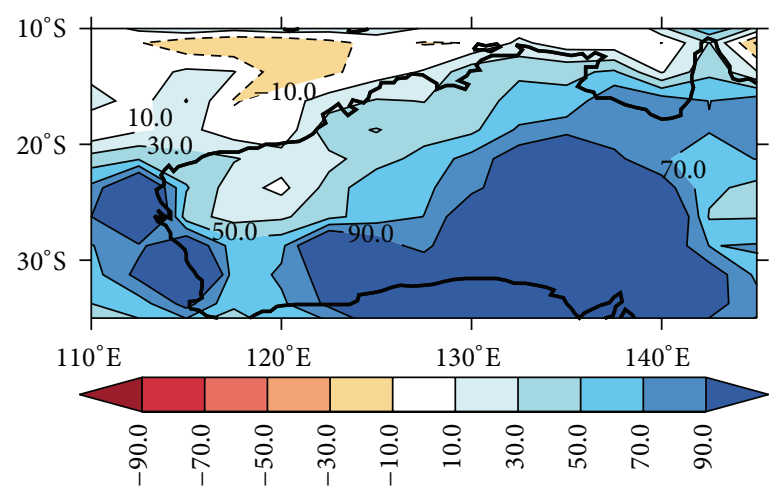

(\%)

(f) $D_{\mathrm{pr}} \mathrm{A} 1.3-\mathrm{A} 1.0$
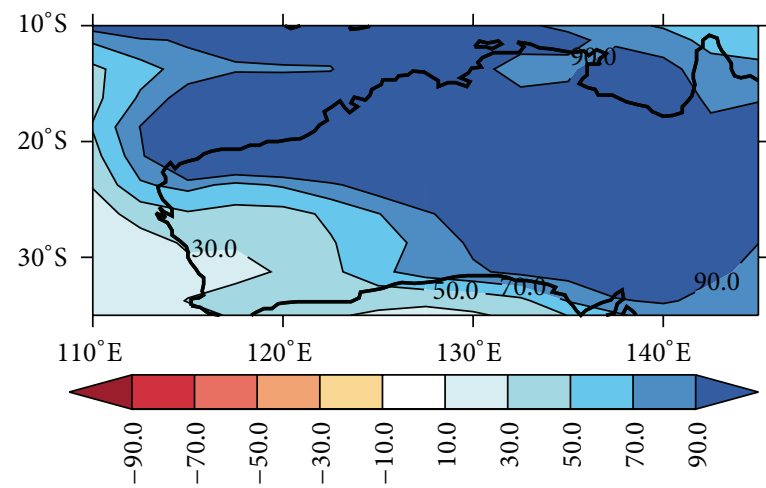

(\%)

(h) $\mathrm{DA}_{\mathrm{c}} \mathrm{A} 1.3-\mathrm{A} 1.1$

FIgure 8: Continued. 


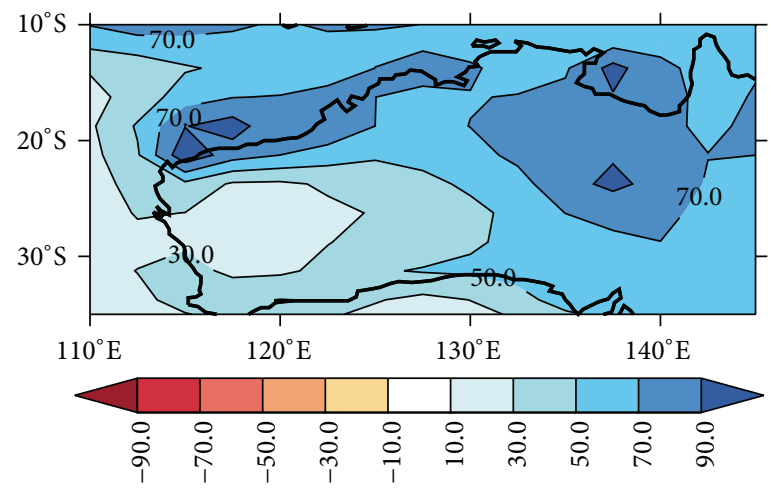

$(\%)$

(i) $\mathrm{DA}_{\mathrm{c}} \mathrm{A} 1.3-\mathrm{Al} .0$

FIGURE 8: The climatological mean (1979-2001) DJF precipitation ( $\mathrm{mm} \mathrm{day}^{-1}$, colored contours) and fractional cloud cover (solid black lines) from (a) A1.0, (b) A1.1, and (c) A1.3. The percentage difference in precipitation for (d) A1.1 relative to A1.0, (e) A1.3 relative to A1.1, and (f) A1.3 relative to A1.0. The percentage change in cloud fraction for (g) A1.1 relative to A1.0, (h) A1.3 relative to A1.1, and (i) A1.3 relative to A1.0.

the diurnal temperature range (DTR) in climate models with higher thermal inertia causing a smaller DTR and vice versa. Moreover, they indicate that the thermal inertia is dependent on the soil water content with higher soil water contents corresponding to increased thermal inertia. The differences in the total soil water content over Australia for A1.1 relative to A1.0 are plotted in Figure 10. Despite A1.1 simulating drier conditions at the surface over Australia than A1.0, A1.1 has higher soil moisture contents throughout the depth of the soil (Figure 10), which would result in a higher thermal inertia and a smaller DTR. This is consistent with the lower daytime and higher nocturnal surface air temperatures.

The differences in the diurnal temperature range subsequently affect the low-level circulation. The reduced surface and low-level air temperatures in A1.1 relative to A1.0 at 1400 AWST act to reduce the amount of dry convection, and therefore convergence, within the heat low. This reduced convergence can be seen in Figure $4(\mathrm{f})$ at $925-850 \mathrm{hPa}$. At night, surface cooling causes the nocturnal boundary layer to form, which reduces the low-level drag and causes the increased convergence within the heat low. This is observed at 2000 AWST in A1.0 (see Figures 2(c) and 3(c), described in more detail in $[2,15,16,34])$; however, the convective mixing will continue for longer in A1.1 as the surface cools slower than in A1.0 between 1400 AWST and 2000 AWST (Figures $7(\mathrm{c})$ and $7(\mathrm{~g}))$. This causes the low-level drag to be larger in A1.1 than A1.0, which reduces the strength of the flow directed towards the centre of the heat low and causes the weakened convergence (see Figure 4(g)).

4.2. A1.3 Relative to A1.1. Across the whole of Australia, except the far south and west, the atmosphere below $800 \mathrm{hPa}$ is cooler throughout the whole day in A1.3 relative to A1.1 (Figures 5(a)-5(d)). The largest temperature differences (approximately $-1.5 \mathrm{~K}$ ) occur over north Australia at 1400 and 2000 AWST (Figures 5(b) and 5(c)). Nonetheless, the atmosphere above $700 \mathrm{hPa}$ is consistently $\sim 2 \mathrm{~K}$ warmer in A1.3 than in A1.1 (Figures 5(e)-5(h)).
The differences in the DJF-mean precipitation and cloud cover are plotted in Figures $8(\mathrm{e})$ and $8(\mathrm{~h})$. The change to the PC2 plus "Tripleclouds" cloud scheme (from now PC2T) causes a systematic increase in cloud cover and precipitation over Australia in A1.3 relative to A1.1 and is consistent with the change in the vertical temperature profiles in Figures $5(\mathrm{e})-5(\mathrm{~h})$. The presence of increased cloud acts to reduce the amount of solar radiation reaching the surface, which causes the air temperature to be lower in A1.3 than A1.1 below $800 \mathrm{hPa}$. Conversely, the increase in latent heating from the presence of the increased cloud cover would act to increase the air temperatures above $700 \mathrm{hPa}$. Moreover, the largest negative differences in $925 \mathrm{hPa}$ temperatures in $\mathrm{A} 1.3$ relative to A1.1 occur where the monsoon precipitation is highest (cf. Figures 5(b) and 5(c) with Figures 8(b) and 8(c)). Therefore, it appears that the inclusion of PC2T has a stronger impact on the local monsoon circulation (and convection) than the heat low.

Overall, the differences between A1.3 and A1.1 are not as strong as the differences between A1.1 and A1.0 at low-levels (below $800 \mathrm{hPa}$ ). Above $700 \mathrm{hPa}$, due to the significant change in cloud physics in A1.3, the opposite is true.

4.3. A1.3 Relative to A1.0. The differences in the circulation and temperature between A1.3 and A1.0 (Figure 6) are a linear combination of the differences between A1.3 relative to A1.1 and A1.1 relative to A1.0 (not shown as the sums of those differences are $<10^{-8}$ ). Therefore there is no nonlinear interaction between CABLE1.8 and PC2T physics when they are used together in A1.3.

The reduced $925 \mathrm{hPa}$ temperatures in $\mathrm{A} 1.3$ relative to A1.0 are primarily caused by CABLE1.8 but reduced further by PC2T (Figure 6(b)). The A1.3 simulation is also warmer over north-west Australia than A1.0 (as with A1.1), which is caused by using CABLE1.8 instead of MOSES; however, the difference in $925 \mathrm{hPa}$ temperature is lower between A1.3 and A1.0 than A1.1 and A1.0 due the low-level cooling caused by $\mathrm{PC} 2 \mathrm{~T}$ and the presence of increased precipitation and cloud 

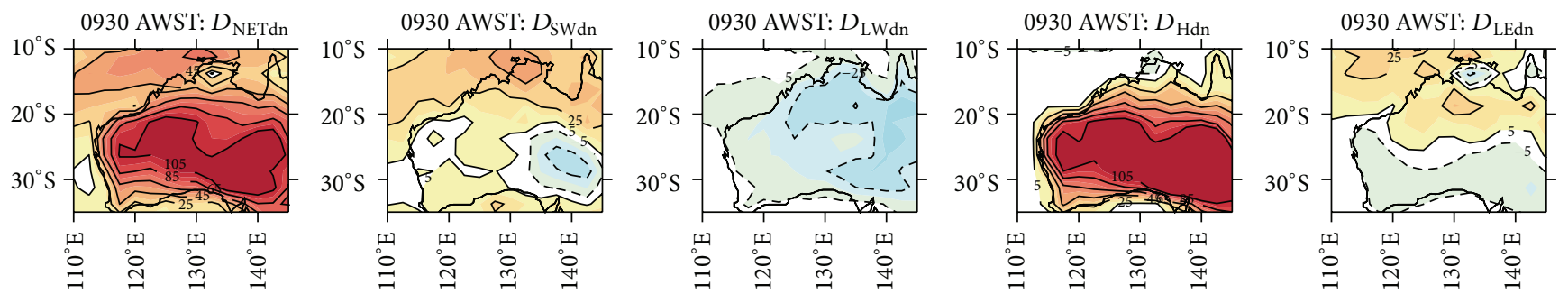

1230 AWST: $D_{\text {NETdn }}$
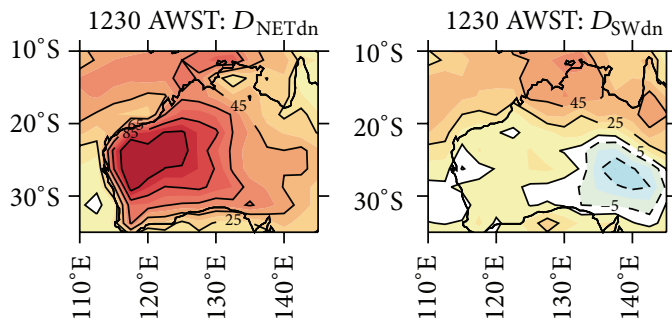

1230 AWST: $D_{\text {LWdn }}$
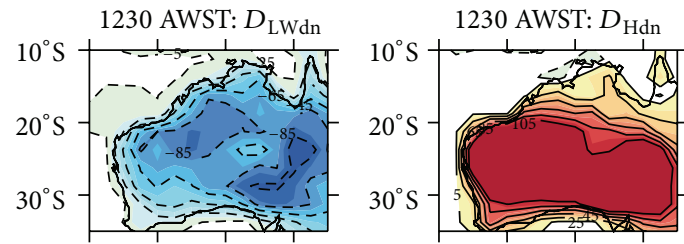

1230 AWST: $D_{\text {LEdn }}$

1530 AWST: $D_{\text {NETdn }}$
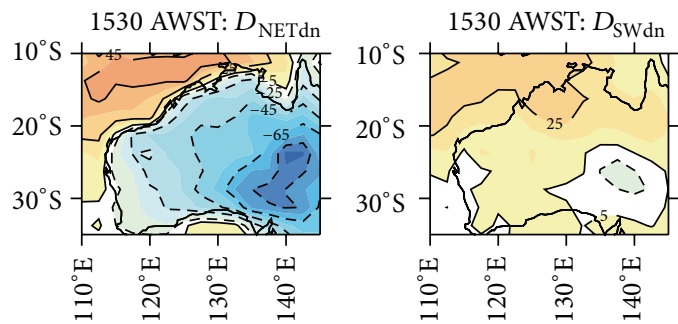

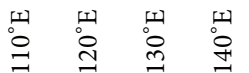

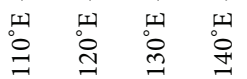

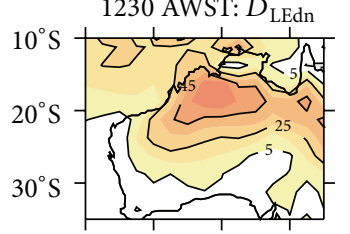

1530 AWST: $D_{\text {LWdn }}$
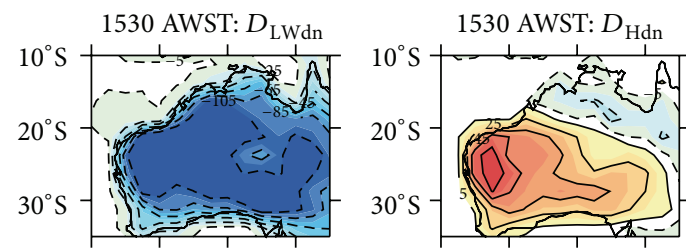

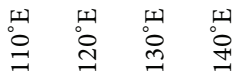

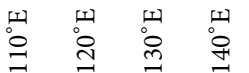

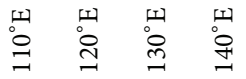
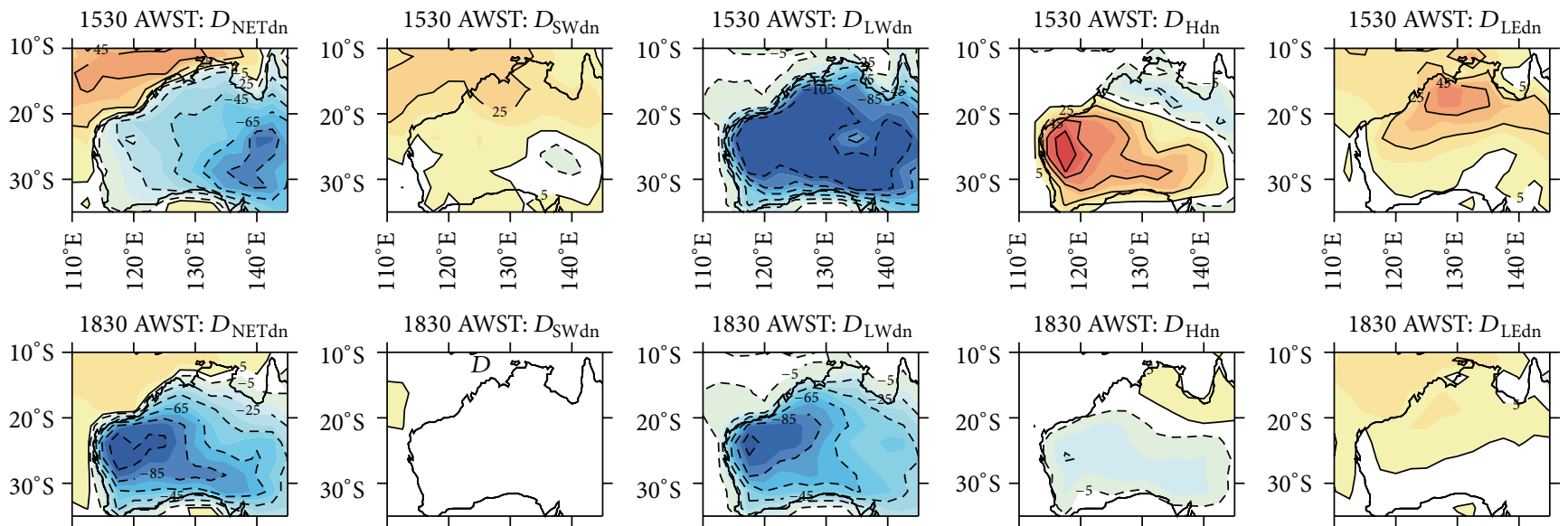

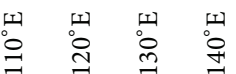
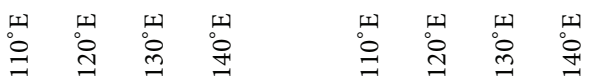

2130 AWST: $D_{\text {NETdn }}$

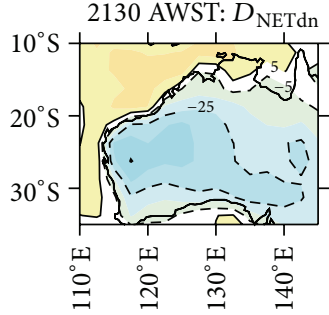

2130 AWST: $D_{\text {SWdn }}$

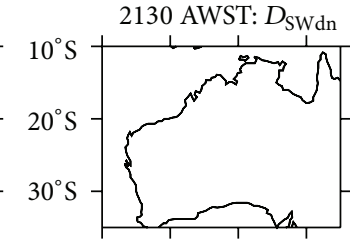

2130 AWST: $D_{\text {LWdn }}$
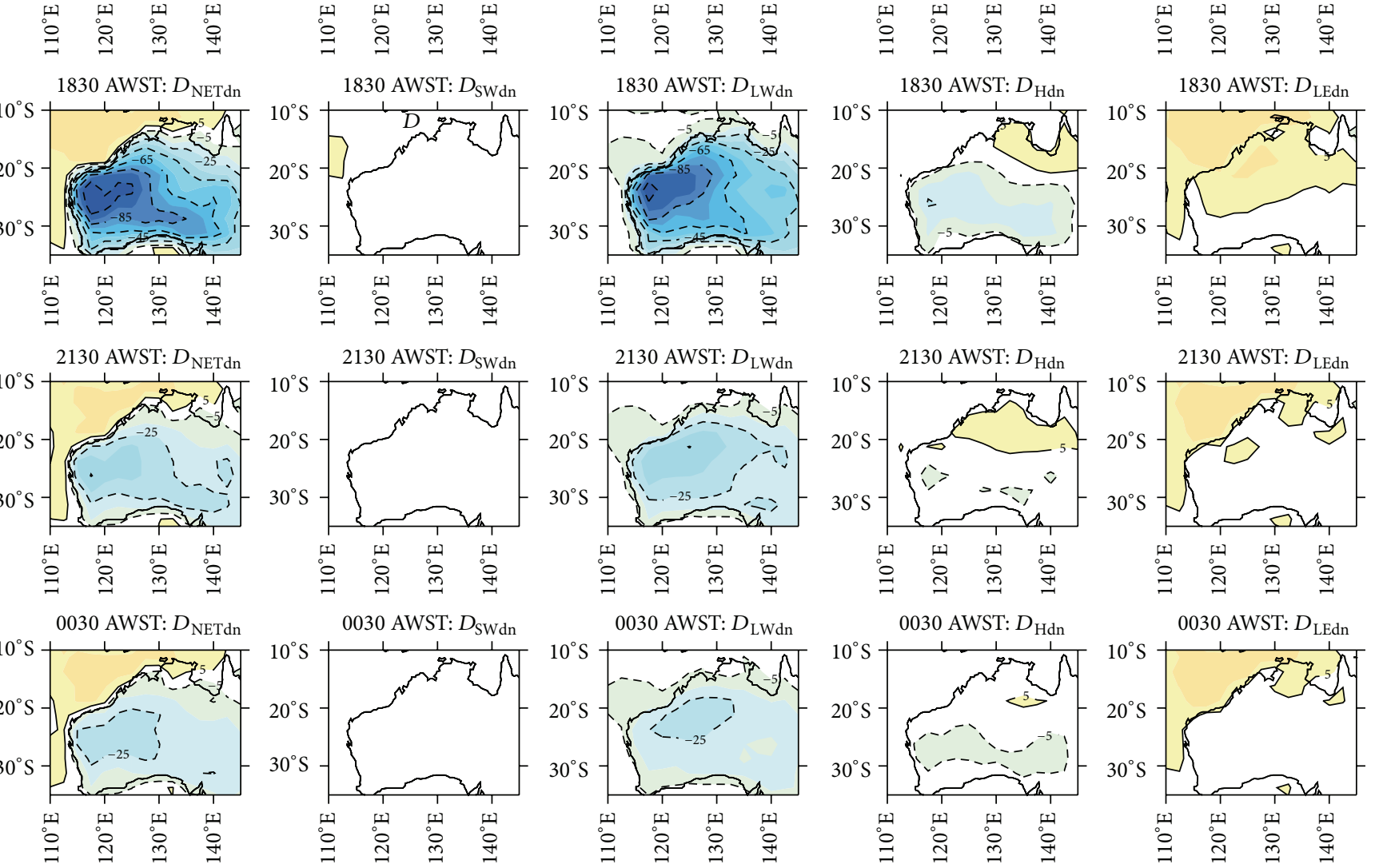

0330 AWST: $D_{\text {NETdn }}$
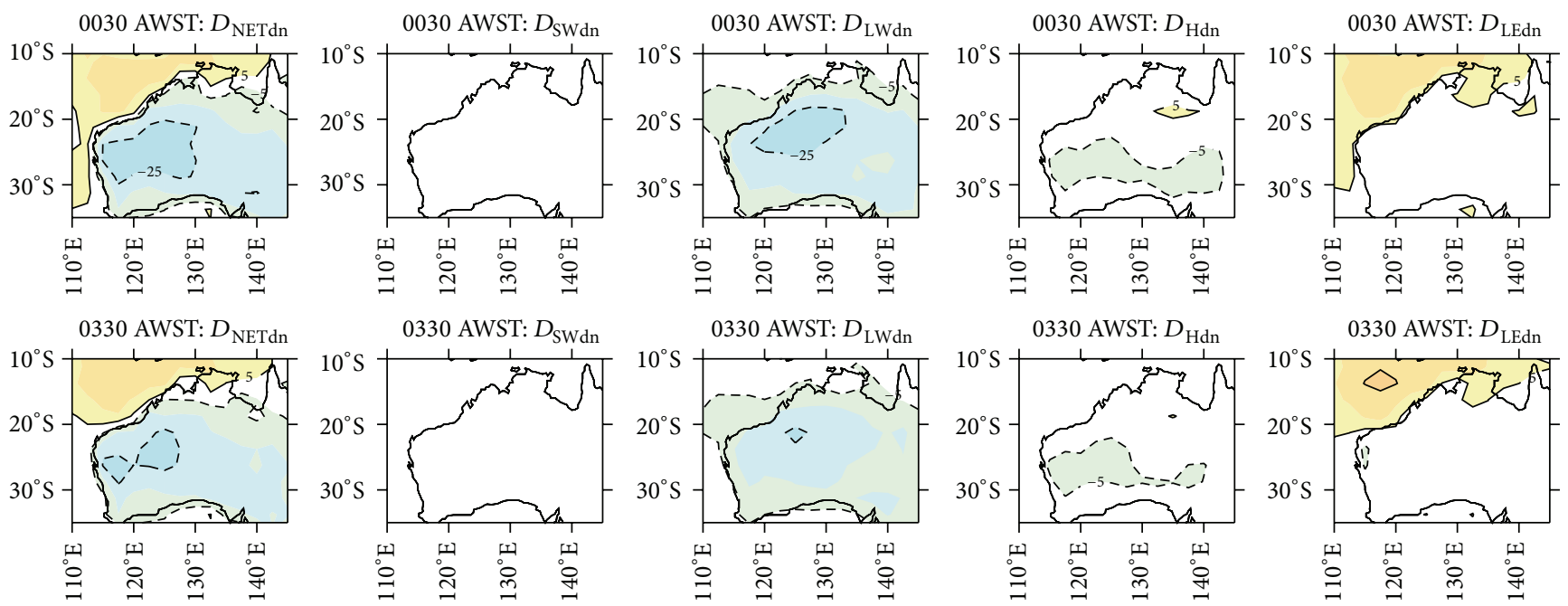

Figure 9: Continued. 


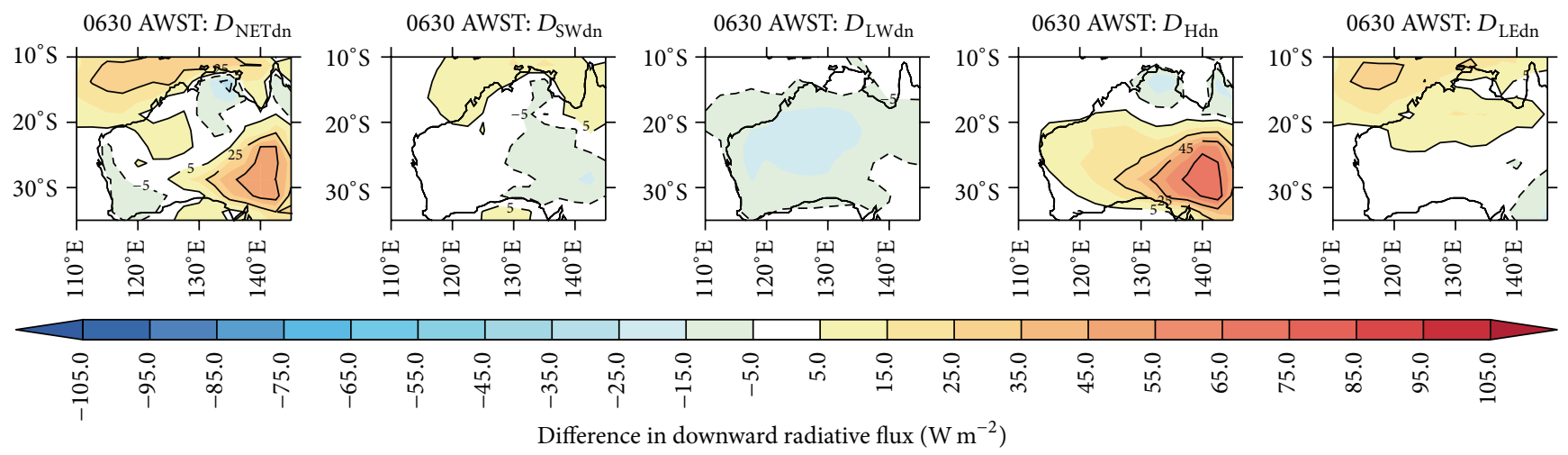

Figure 9: The difference between A1.1 and A1.0 climatological (1979-2001) mean 3-hourly downward radiative fluxes (W m ${ }^{-2}$ ) at the surface. Column 1: net radiative flux $\left(D_{\text {NETdn }}\right)$; column 2: short-wave radiative flux $\left(D_{\text {SWdn }}\right)$; column 3: long-wave radiative flux $\left(D_{\text {LWdn }}\right)$; column 4 : sensible heat flux $\left(D_{\mathrm{Hdn}}\right)$; column 5: latent heat flux $\left(D_{\mathrm{LEdn}}\right)$. Time averages are centred on (from row 1 to row 8) 0930 AWST, 1230 AWST, 1530 AWST, 1830 AWST, 2130 AWST, 0030 AWST, 0330 AWST, and 0630 AWST.

cover (see Figures 8(f) and 8(i)). The increased cloud cover also causes the air temperatures above $650 \mathrm{hPa}$ to be warmer in A1.3 relative to A1.0, which resembles the differences between A1.3 and A1.1 and suggests that the differences are driven by using PC2T. Despite the changes in air temperature caused by the different cloud physics in A1.3 relative to A1.1, the changes in circulation around the heat low are much weaker than those caused by changing the surface scheme from MOSES (A1.0) to CABLE1.8 (A1.1). Therefore, in terms of modelling the north-west Australian heat low system, the differences between A1.1 and A1.0 are more significant.

\section{Conclusions and Further Work}

The aims of this work were to document and discuss the representation of the summertime heat low circulation over north-west Australia in three different configurations of the same GCM (ACCESS). Moreover, this study also aimed at identifying the processes that caused the simulated heat low structure to differ in each simulation.

The main results of this work are as follows:

(i) The differences in the $925 \mathrm{hPa}$ circulation between each configuration of the model are comparable to the differences between each model and the reanalyses (Figure 1).

(ii) The nocturnal convergence into the heat low is stronger in the A1.0 (MOSES) simulation than in A1.1 (CABLE1.8) (Figure 4).

(iii) The low-level atmosphere in A1.0 heats up faster during the day and cools down faster at night than in A1.1 (Figure 7).

(iv) The difference in surface heating and cooling rates between A1.0 and Al.1 appear to be driven by differences in the thermal inertia of the soil used by MOSES and CABLE1.8 (Figures 9 and 10).

(v) The simulated air flow in the north-Australian monsoon region is more convergent in $\mathrm{A} 1.3$ (PC2T) than

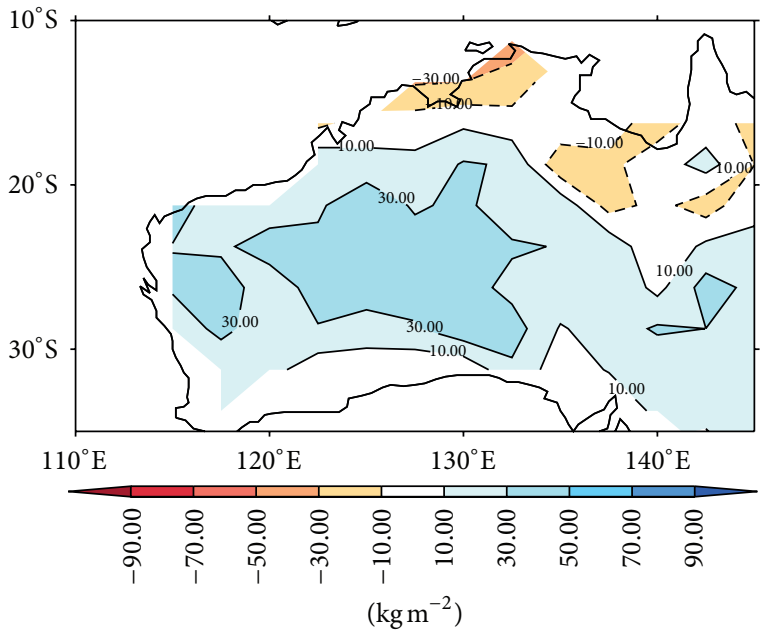

FIGURE 10: The difference in the total soil moisture content $\left(\mathrm{kg} \mathrm{m}^{-2}\right)$ between A1.1 and A1.0 averaged over all DJFs from 1979 to 2001.

A1.1 (non-PC2T) but there is little impact on the heat low circulation (Figure 5).

(vi) The changes in cloud cover and precipitation in A1.3 relative to A1.1 cause lower air temperatures below $800 \mathrm{hPa}$ and higher air temperatures above $700 \mathrm{hPa}$ (Figure 5).

(vii) The heat low is more sensitive to changes in the surface parameterization (MOSES versus CABLE1.8) than the cloud cover and convection (diagnostic clouds versus PC2T).

This work has shown the impact of changing the parameterized processes in ACCESS on the simulated circulation over north-west Australia. Moreover, the study shows that the differences in circulation associated with these perturbations are comparable with the errors relative to the reanalyses. Attributing circulation errors to specific parameterized processes is difficult to do when evaluating GCM simulations (such as those used in CMIP5) as the parameterizations are 
likely to be configured differently in each model. In this study, however, since the parameterized processes were changed individually (and in combination), the impact of changing the surface and cloud schemes on the circulation could be quantified.

The next logical step for this work is to test the hypothesis discussed in Section 4.1 to see whether the larger soil water contents in the A1.1 simulation are responsible for the smaller DTR relative to A1.0. If reducing the soil water content in A1.1 results in an increase in the DTR such that it becomes almost identical to that of A1.0, then the result would imply that the amount of water stored in the soil is more important in determining the interaction between the land surface and the lower atmosphere than the configuration of the surface scheme employed. This would allow model developers to target the representation of subsurface soil moisture properties as a priority in arid and semiarid land areas such as north-west Australia.

\section{Conflict of Interests}

The authors declare that there is no conflict of interests regarding the publication of this paper.

\section{Acknowledgments}

Both Matthew M. Allcock and Duncan Ackerley were supported by the ARC Centre of Excellence for Climate System Science (CE110001028). The ACCESS simulations were undertaken with the assistance of resources from the National Computational Infrastructure (NCI), which is supported by the Australian Government. Finally, ERA-Interim reanalysis data were supplied by the European Centre for MediumRange Weather Forecasts.

\section{References}

[1] Z. Rácz and R. K. Smith, “The dynamics of heat lows," Quarterly Journal of the Royal Meteorological Society, vol. 125, no. 553, pp. 225-252, 1999.

[2] T. Spengler, M. J. Reeder, and R. K. Smith, "The dynamics of heat lows in simple background flows," Quarterly Journal of the Royal Meteorological Society, vol. 131, no. 612, pp. 3147-3165, 2005.

[3] S. J. Arnup and M. J. Reeder, "The diurnal and seasonal variation of the northern Australian dryline," Monthly Weather Review, vol. 135, no. 8, pp. 2995-3008, 2007.

[4] S. J. Arnup and M. J. Reeder, "The structure and evolution of the northern Australian dry line," Australian Meteorological and Oceanographic Journal, vol. 58, no. 4, pp. 215-231, 2009.

[5] G. Berry, M. J. Reeder, and C. Jakob, "Physical mechanisms regulating summertime rainfall over Northwestern Australia," Journal of Climate, vol. 24, no. 14, pp. 3705-3717, 2011.

[6] A. Uriate, "Rainfall on the Northern coast of the Iberian peninsula," Journal of Meteorology, vol. 5, pp. 138-144, 1980.

[7] M. A. Gaertner, C. Fernandez, and M. Castro, "A twodimensional simulation of the Iberian summer thermal low," Monthly Weather Review, vol. 121, no. 10, pp. 2740-2756, 1993.
[8] S. Alonso, A. Portela, and C. Ramis, "First considerations on the structure and development of the Iberian thermal low-pressure system," Annales Geophysicae, vol. 12, no. 5, pp. 457-468, 1994.

[9] A. Portela and M. Castro, "Summer thermal lows in the Iberian peninsula: a three-dimensional simulation," Quarterly Journal of the Royal Meteorological Society, vol. 122, no. 529, pp. 1-22, 1996.

[10] C. S. Ramage, Monsoon Meteorology, Academic Press, New York, NY, USA, 1971.

[11] D. E. Pedgley, "Desert depressions over North-East Africa," The Meteorological Magazine, vol. 101, pp. 228-244, 1972.

[12] J. F. Griffiths and K. H. Soliman, "The northern desert," in World Survey of Climatology, Vol. 10, Climates of Africa, J. F. Griffiths, Ed., pp. 75-111, Elsevier, 1972.

[13] D. J. Parker, R. R. Burton, A. Diongue-Niang et al., "The diurnal cycle of the West African monsoon circulation," Quarterly Journal of the Royal Meteorological Society, vol. 131, no. 611, pp. 2839-2860, 2005.

[14] R. Suppiah, "The Australian summer monsoon: a review," Progress in Physical Geography, vol. 16, no. 3, pp. 283-318, 1992.

[15] D. Ackerley, G. Berry, C. Jakob, and M. J. Reeder, "The roles of diurnal forcing and large-scale moisture transport for initiating rain over northwest Australia in a GCM," Quarterly Journal of the Royal Meteorological Society, vol. 140, no. 685, pp. 2515-2526, 2014.

[16] D. Ackerley, G. Berry, C. Jakob, M. J. Reeder, and J. Schwendike, "Summertime precipitation over northern Australia in AMIP simulations from CMIP5," Quarterly Journal of the Royal Meteorological Society, vol. 141, no. 690, pp. 1753-1768, 2015.

[17] T. Keenan, K. Puri, T. Hirst et al., "Next generation Australian community climate and earth-system simulator (NG-ACCESS) a Roadmap 2014-2019," CAWCR Technical Report 075, Bureau of Meteorology, Melbourne, Australia, 2014, http://www.cawcr .gov.au/publications/technicalreports/CTR_075.pdf.

[18] K. Puri, G. Dietachmayer, P. Steinle et al., "Implementation of the initial ACCESS numerical weather prediction system," Australian Meteorological and Oceanographic Journal, vol. 63, no. 2, pp. 265-284, 2013.

[19] D. Bi, M. Dix, S. J. Marsland et al., "The ACCESS coupled model: description, control climate and evaluation," Australian Meteorological and Oceanographic Journal, vol. 63, no. 1, pp. 4164, 2013.

[20] T. Davies, M. J. P. Cullen, A. J. Malcolm et al., "A new dynamical core of the Met Office's global and regional modelling of the atmosphere," Quarterly Journal of the Royal Meteorological Society, vol. 131, no. 608, pp. 1759-1782, 2005.

[21] G. M. Martin, N. Bellouin, W. J. Collins et al., "The HadGEM2 family of Met Office Unified Model climate configurations," Geoscientific Model Development, vol. 4, no. 3, pp. 723-757, 2011.

[22] E. A. Kowalczyk, Y. P. Wang, R. M. Law, H. L. Davies, J. L. McGregor, and G. Abramowitz, "The CSIRO atmosphere biosphere land exchange (CABLE) model for use in climate models and as an offline model," Marine and Atmospheric Research Paper 013, CSIRO, Clayton South, Australia, 2006, http://www.cmar.csiro .au/e-print/open/kowalczykea_2006a.pdf.

[23] E. A. Kowalczyk, L. Stevens, R. M. Law et al., "The land surface model component of ACCESS: description and impact on the simulated surface climatology," Australian Meteorological and Oceanographic Journal, vol. 63, no. 1, pp. 65-82, 2013.

[24] J. K. P. Shonk and R. J. Hogan, "Tripleclouds: an efficient method for representing horizontal cloud inhomogeneity in 
1D Radiation schemes by using three regions at each height," Journal of Climate, vol. 21, no. 11, pp. 2352-2370, 2008.

[25] Z. Sun, C. Franklin, X. Zhou et al., "Modifications in atmospheric physical parameterization for improving SST simulation in the ACCESS coupled model," Australian Meteorological and Oceanographic Journal, vol. 63, no. 1, pp. 233-247, 2013.

[26] R. N. B. Smith, "A scheme for predicting layer clouds and their water content in a general circulation model," Quarterly Journal Royal Meteorological Society, vol. 116, no. 492, pp. 435-460, 1990.

[27] D. R. Wilson, R. N. B. Smith, D. Gregory, C. Wilson, A. C. Bushell, and S. Cusack, "The large-scale cloud scheme and saturated specific humidity," Unified Model Documentation Paper 26, Met Office, Exeter, UK, 2004.

[28] D. R. Wilson, A. C. Bushell, A. M. Kerr-Munslow, J. D. Price, and C. J. Morcrette, "PC2: a prognostic cloud fraction and condensation scheme. I. Scheme description," Quarterly Journal of the Royal Meteorological Society, vol. 134, no. 637, pp. 20932107, 2008.

[29] D. R. Wilson, A. C. Bushell, A. M. Kerr-Munslow, J. D. Price, C. J. Morcrette, and A. Bodas-Salcedo, "PC2: a prognostic cloud fraction and condensation scheme. II: climate model simulations," Quarterly Journal of the Royal Meteorological Society, vol. 134, no. 637, pp. 2109-2125, 2008.

[30] C. N. Franklin, C. Jakob, M. Dix, A. Protat, and G. Roff, "Assessing the performance of a prognostic and a diagnostic cloud scheme using single column model simulations of TWPICE," Quarterly Journal of the Royal Meteorological Society, vol. 138, no. 664, pp. 734-754, 2012.

[31] W. L. Gates, "AMIP: the Atmospheric Model Intercomparison Project," Bulletin of the American Meteorological Society, vol. 73, no. 12, pp. 1962-1970, 1992.

[32] W. L. Gates, J. S. Boyle, C. Covey et al., "An overview of the results of the Atmospheric Model Intercomparison Project (AMIP I)," Bulletin of the American Meteorological Society, vol. 80, no. 1, pp. 29-55, 1999.

[33] D. P. Dee, S. M. Uppala, A. J. Simmons et al., “The ERA-Interim reanalysis: configuration and performance of the data assimilation system," Quarterly Journal of the Royal Meteorological Society, vol. 137, no. 656, pp. 553-597, 2011.

[34] T. Spengler and R. K. Smith, "The dynamics of heat lows over flat terrain," Quarterly Journal of the Royal Meteorological Society, vol. 134, no. 637, pp. 2157-2172, 2008.

[35] A. Dai, K. E. Trenberth, and T. R. Karl, "Effects of clouds, soil moisture, precipitation, and water vapor on diurnal temperature range," Journal of Climate, vol. 12, no. 8, pp. 2451-2473, 1999.

[36] S. Aït-Mesbah, J. L. Dufresne, F. Cheruy, and F. Hourdin, “The role of thermal inertia in the representation of mean and diurnal range of surface temperature in semiarid and arid regions," Geophysical Research Letters, vol. 42, 2015. 

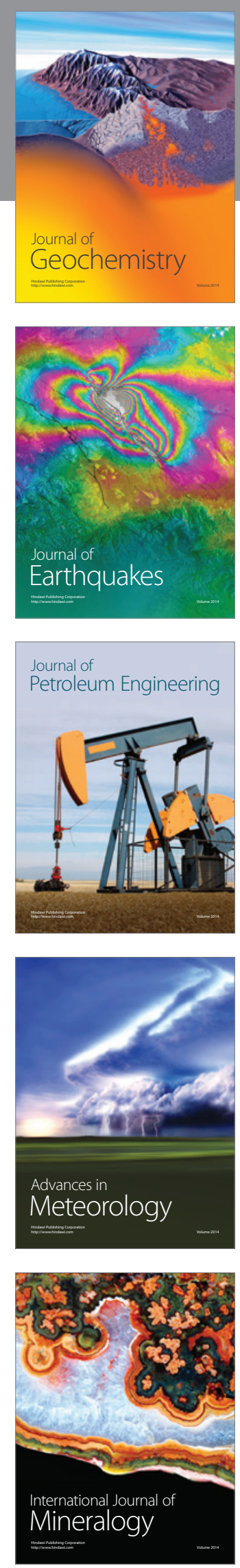
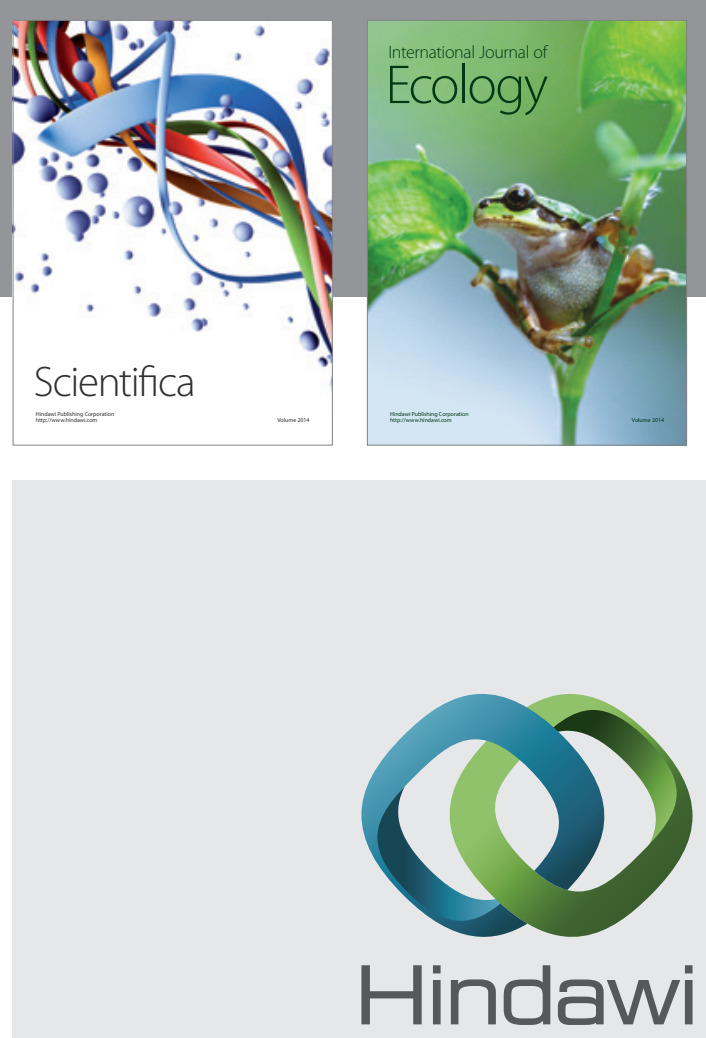

Submit your manuscripts at

http://www.hindawi.com
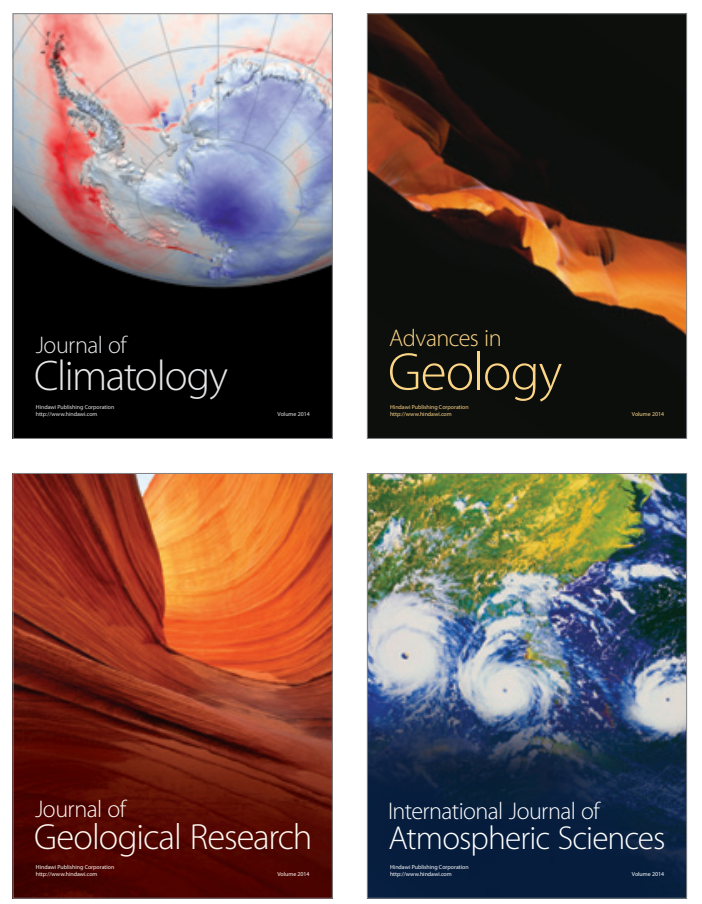

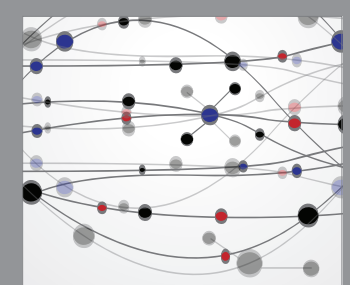

The Scientific

\section{World Journal}
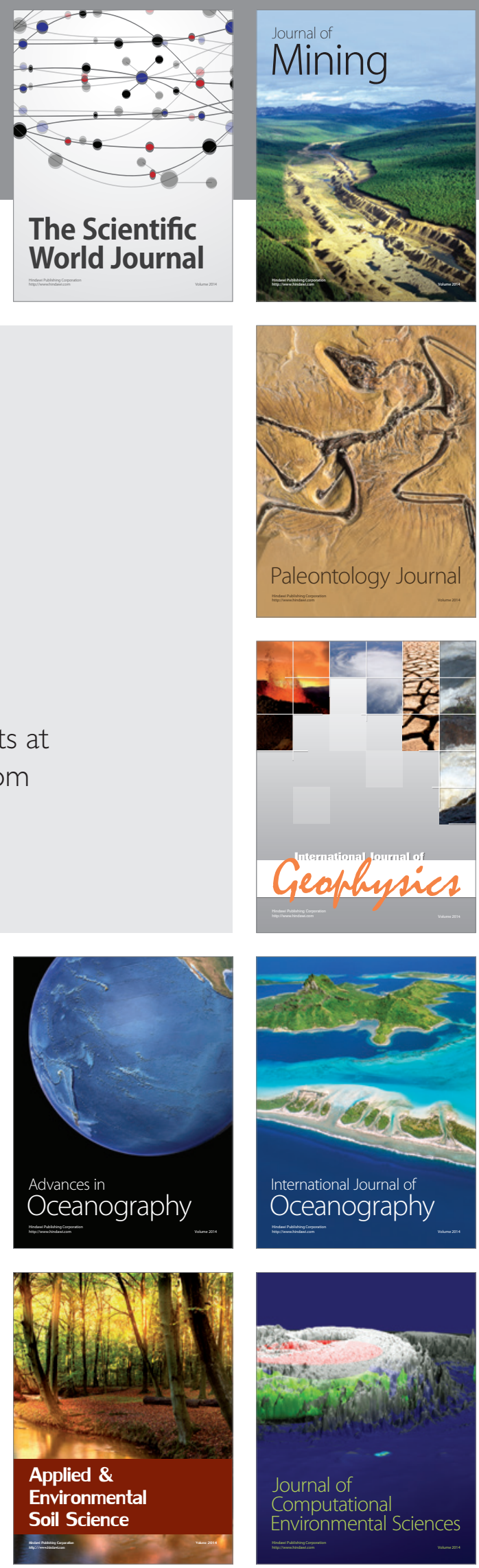